\title{
Analysis and Ground Test of Aerothermal Effects on Spherical Capsule Geometries
}

\author{
Matthew MacLean ${ }^{*}$ \\ Erik Mundy* \\ Timothy Wadhams* \\ Michael Holden ${ }^{\dagger}$ \\ CUBRC, Aerothermal/Aero-optics Evaluation Center, Buffalo, NY, 14225 \\ Ronald Parker* \\ Stratonics, Fredonia, NY 14435
}

\begin{abstract}
A review is presented of ground test experiments of a 146-mm spherical capsule model with forebody and aftbody symmetry plane measurements of heating and pressure for a range of enthalpies and Reynolds numbers to obtain a dataset of fundamental validation data for CFD codes and to develop a database for design-of-experiment of future studies. Comparisons with laminar experiments are made using CFD demonstrating the influence of thermochemical non-equilibrium on the aerodynamic and aerothermal character of the body. For laminar flows in nitrogen up to $10 \mathrm{MJ} / \mathrm{kg}$, the good agreement with available measurements suggests that the description of the chemical and thermal activity of the gas is adequate. Analysis of the forebody heating found that a catalytic recombination probability of 0.002 to 0.010 was required to match the measured heat flux. For laminar flows in air up to $14 \mathrm{MJ} / \mathrm{kg}$, some significant differences between CFD and measurements highlight the inadequacy of the current chemical and thermal models to predict the state of the gas after the rapid expansion in the nozzle. Analysis of forebody heating in these cases found that catalytic recombination probability near 1.0 was required to match measured heat flux, suggesting that potentially some type of excitation may be involved that is not properly modeled. Finally, the non-equilibrium excitation may be collision related as limited evidence suggests that the phenomenon becomes more benign as the number of collisions increases.
\end{abstract}

\section{Introduction}

A s part of a much larger program to study thermochemical effects on relevant geometries in the LENS facility, Lexperiments have been performed on a 146-mm spherical (Apollo-style) capsule to better design future ground tests of CEV/CRV geometries. The overview of this real-gas program has been given by Holden, et al. ${ }^{1}$, and includes (1) fundamental measurements of facility and numerical validation through laser-diode measurements of nitric oxide concentration, temperature, and velocity in the freestream of the test section, (2) fundamental measurements of shock shape and surface heating on simple cylinder and hemisphere geometries, (3) blunt body heating and laminar-turbulent transition stability on the forebody and wake of a generic spherical capsule, (4) laminar shock-wave/boundary layer interaction on a double cone with vibration/dissociation coupling effects, and (5) laminar shock-wave/boundary layer interaction on a NASA Space Transport System (STS) or Shuttle control surface. The objective of the work has been principally to (1) validate and understand the operation of the facility at high enthalpy conditions, and (2) to generate a database of reliable measurements with which to assess the current computational modeling capabilities in each of these areas. Some work has been published detailing the analysis and comparison with numerical simulations for certain components of this program ${ }^{2,3}$, but the focus of this work is on the generic spherical capsule tests.

The spherical capsule model is a 146-mm capsule with seven forebody pressure taps and six forebody thermocouple heat transfer gages. Additionally, there are four each pressure taps and thin-film heat transfer gages on the aftbody symmetry plane. The forebody data is the primary focus of this paper. Runs are available for both $0^{\mathrm{O}}$

\footnotetext{
* Senior Research Scientist, AIAA Member.

$\dagger$ †AEC Program Manager, AIAA Fellow.
} 
and $28^{\circ}$ angle of attack with both nitrogen and air test gases. The measurements are compared to simulations performed with a chemically reacting, non-equilibrium CFD code. The effect of surface catalysis is explored by simulating a range of surface boundary conditions and comparing to the available experimental measurements to understand the influence of catalytic heating as a function of the total enthalpy of the test gas. The influence of the test medium on the thermochemical non-equilibrium modeling is explored by contrasting the solutions obtained in pure nitrogen against the more reactive air constituents. In total, eleven runs are considered where laminar flow was measured. Additional runs where transitional heating was measured have not been considered in the scope of this paper.

\section{Experimental Facility Background}

Currently, CUBRC operates the 48" reflected shock tunnel, the LENS-I and LENS-II reflected shock tunnels ${ }^{4}$, and the LENS-XX expansion tunnel ${ }^{5}$ shown in Fig 1. The reflected shock tunnel uses incident and reflected shocks to cleanly heat and pressurize a stagnant test gas to high enthalpy levels. This test gas may then be expanded through a converging-diverging nozzle in a manner similar to a blowdown facility to produce a hypervelocity test flow. Expansion tunnels like LENS-XX also operate as short duration facilities, but an expansion tunnel produces a high enthalpy flow by adding kinetic energy directly to the flow by expanding through an accelerant gas. Because the flow is never stagnated, the expansion tunnel produces a quiescent freestream state that minimizes the thermal and chemical non-equilibrium that occurs in the freestream of reflected shock tunnels at very high enthalpies $(>5 \mathrm{MJ} / \mathrm{kg})$. CUBRC employs both reflected shock and expansion tunnels to provide a wide range of supersonic, hypersonic, and hypervelocity test capabilities, which are summarized in Fig 2. The nominal trajectory planned for the HIFiRE-1 flight is noted along with specific test points duplicated in the facility during the ground test.

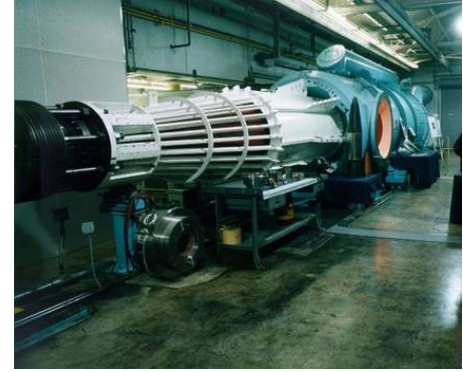

(a) LENS-I

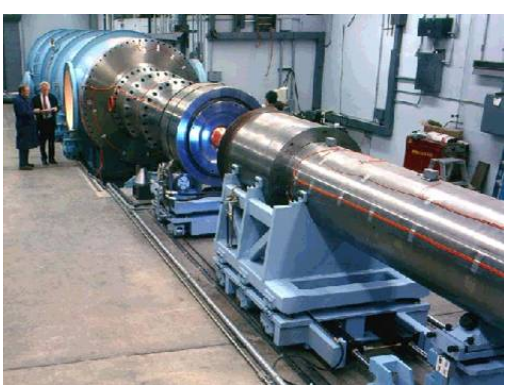

(b) LENS-II

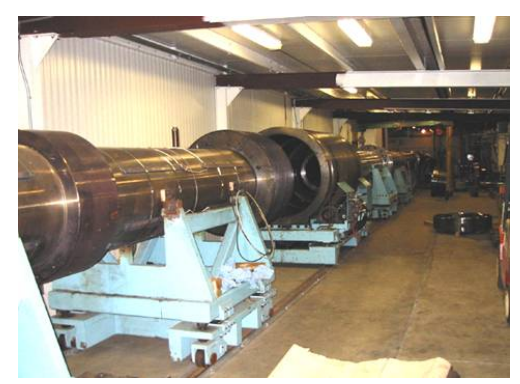

(c) LENS-XX

Figure 1. LENS Facilities at CUBRC

The LENS reflected shock-tunnel facilities were developed primarily to study the full-scale, hypervelocity flow physics of interceptors and airbreathing engine configurations. The scale and flow duplication capabilities of LENS are such that these vehicles can be studied at their full scale, inclusive of effects such as transition to turbulence, turbulent mixing from cross-flow jets and thrusters, duplicated flow chemistry, and other effects that are difficult or impossible to simulate at cold-flow or sub-scale conditions. The reflected shock-tunnel

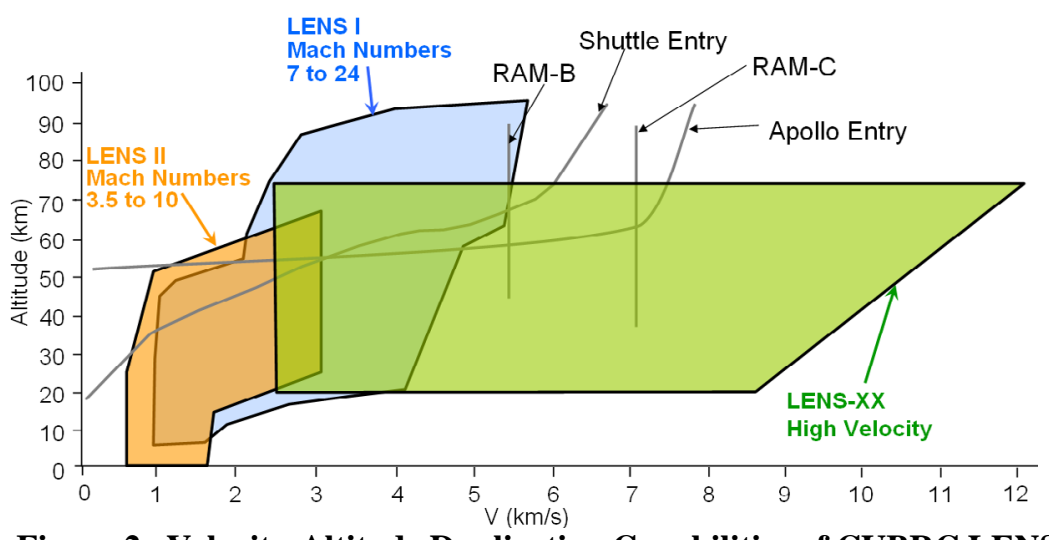

Figure 2. Velocity-Altitude Duplication Capabilities of CUBRC LENS Facilities facilities have been validated with tests of measurements by comparing directly to numerical predictions, including recent work with tunable laser-diode diagnostics ${ }^{3,6}$. Additionally, the facilities have been used to perform studies of fundamental flow phenomena like the double cone with success and to solve practical flight problems on vehicles like the Shuttle STS vehicle. 


\section{Supporting Numerical Tools}

\section{A. Data-Parallel Line-Relaxation (DPLR) Code}

All ground test studies in the LENS facilities are extensively calibrated and validated with numerical tools. The primary CFD tool used is the DPLR code provided by NASA Ames Research Center. DPLR is a multi-block, structured, finite-volume code that solves the reacting Navier-Stokes equations including finite rate chemistry and finite rate vibrational non-equilibrium effects. This code is based on the data-parallel line relaxation $\operatorname{method}^{7}$ and implements a modified (low dissipation) Steger-Warming flux splitting approach ${ }^{8}$ for the convection terms and central differencing for the diffusion terms. Finite rate vibrational relaxation is modeled via a simple harmonic oscillator vibrational degree of freedom ${ }^{9}$ using the Landau-Teller model ${ }^{10}$. Vibrational energy relaxation rates are computed by default from the semi-empirical expression due to Millikan and White ${ }^{11}$, but rates from the work of Camac $^{12}$ and Park, et $\mathrm{al}^{13}$ are substituted for specific collisions where experimental data exists. Vibrationdissociation coupling is currently modeled using the $T-T V$ approach of Park ${ }^{14}$ or with some preliminary implementation of CVDV coupling ${ }^{15}$. Transport properties are appropriately modeled in DPLR for high enthalpy flow ${ }^{16,17}$ using the binary collision-integral based mixing rules from Gupta, et $\mathrm{al}^{18}$. Diffusion coefficients are modeled using the self-consistent effective binary diffusion (SCEBD) method ${ }^{19}$. Turbulence models available in the DPLR code currently include the Baldwin-Lomax 0-equation model ${ }^{20}$, the Spalart-Allmaras model 1-equation model $^{21}$, and the Shear Stress Transport (SST) 2-equation model ${ }^{22}$ each with corrections for compressibility effects $^{23,24}$. Recent relevant capabilities of the DPLR code involve automated grid adaptation to improve solution quality $^{25}$.

\section{B. Candler Nozzle Code}

Additionally, a specialized code has been developed by Candler $^{26}$ to compute the nozzle flowfield for a highpressure, high-enthalpy ground test facility by employing a modified equation of state for very dense gases ${ }^{27}$. This code shares much of its heritage with the NASA Ames DPLR code (described in A above) as it employs the same flux splitting and time integration treatments. The nozzle code has been streamlined by hardwiring parts of the code to solve for a single-block, axisymmetric nozzle with fixed boundary conditions. These modifications lead to a substantial decrease in required solution time and allow us to compute the nozzle flowfield in the same length of time that it requires to set-up and make a run in the LENS facilities (about 2 hours).

The nozzle code employs the Spalart-Allmaras ${ }^{21}$ one-equation turbulence model with the Catris and Aupoix compressibility correction ${ }^{24}$. This turbulence formulation has been shown to adequately predict the displacement of the turbulent boundary layer in the throat region of the nozzle and subsequent boundary layer distortion caused by the rapid reduction in local Reynolds number in the diverging section of the nozzle. We have demonstrated this agreement through comparisons with measured Pitot pressure profiles in the freestream in several previous publications $^{28}$. At low to medium enthalpy levels with moderate levels of chemical and vibrational non-equilibrium the method has been found to predict a freestream state that correlates accurately with measurements made in the test section. However, at high enthalpies where there is significant chemical and thermal activity, questions remain about the capability of the physical model to describe the very rapid expansion from reservoir to the test section ${ }^{29,30}$.

\section{Model and Test Conditions}

The portion of the test program under investigation is a spherical capsule that closely resembles the generic OML of the Apollo or CEV reentry vehicles. The model was constructed and tested as part of a fundamental research effort within the AFOSR Center of Excellence in Hypersonics, a joint effort between CUBRC and the University of Minnesota. The goal of this effort has been to characterize the facility and provide CFD and physical model validation test cases at high enthalpy levels using geometry that is relevant to upcoming CEV development by NASA for U.S. space interests. The CAD model of this test article is shown in Fig 3. The forebody of the vehicle is spherical with a major diameter of 146-mm (5.75") and a shoulder radius which is $5 \%$ of the major diameter or 7.32$\mathrm{mm}$. The aftshell of the test article is $32.5^{\circ}$. The model is mounted in the facility on split sting rods near the back of the vehicle with the idea that the lateral location of the supports will allow flow to pass unimpeded on the symmetry plane of the flowfield. The sting was mounted in two possible positions on the model, one to place the capsule at $0^{\mathrm{O}}$ angle of attack and one to place it at $28^{\mathrm{O}}$ angle of attack. The first condition was selected to obtain axisymmetric code validation cases (except in the region of the sting supports) that are easily interpretable and enticing for CFD analysis. The axisymmetric condition also results in the highest degree of dissociation on the forebody of the model. The second orientation was selected because it is nominally the peak L/D orientation of the geometry, which is 
realistic for the study of reentry effects including stability and control of the capsule. Dimensions of the model and support structure are given in Fig 4.

The capsule was instrumented with six coaxial thermocouple gages and seven pressure gages on the forebody of the capsule. The aftshell was instrumented with four each of thin-film gages and pressure gages. All instrumentation was placed on the symmetry plane of the model. At zero degrees angle of attack, the forebody sensors are geometrically symmetric about the stagnation line and provide a measure of repeatability. The locations of the instrumentation are shown in Fig 5. The thermocouple gages are chromel/constantan gages with a chromium surface coating. The short duration tunnel event allows for the solution for heat flux via one-dimensional conduction analysis given the measured surface temperature history. The measurement of heat flux with these devices has been compared to the same measurements made with thin-film gages, which is a platinum resistance thermometer (PRT) on an insulating substrate. The results have been shown to correlate well between the two techniques for all kinds of shapes and flows. The response of the different gage types in the presence of catalytic heating is a subject of active debate, but evidence has so far indicated that the response of each device is about the same despite the fact that different surface materials are exposed to the gas/surface interface ${ }^{31}$. In general, the trade-off between the two technologies is that the thin-film gages are significantly more sensitive and exhibit less noise in the signal while the thermocouple gages are significantly more robust in harsh environments. For this reason, the forebody gages were selected as thermocouples while thin-films were used on the aftshell. The pressure gages used on the model were

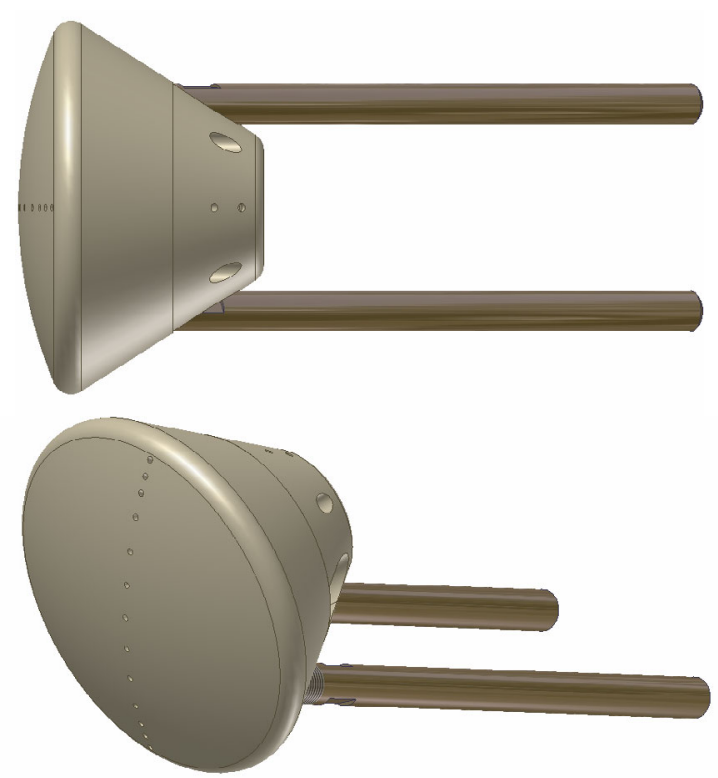

Figure 3. CAD Model of Generic Spherical Capsule

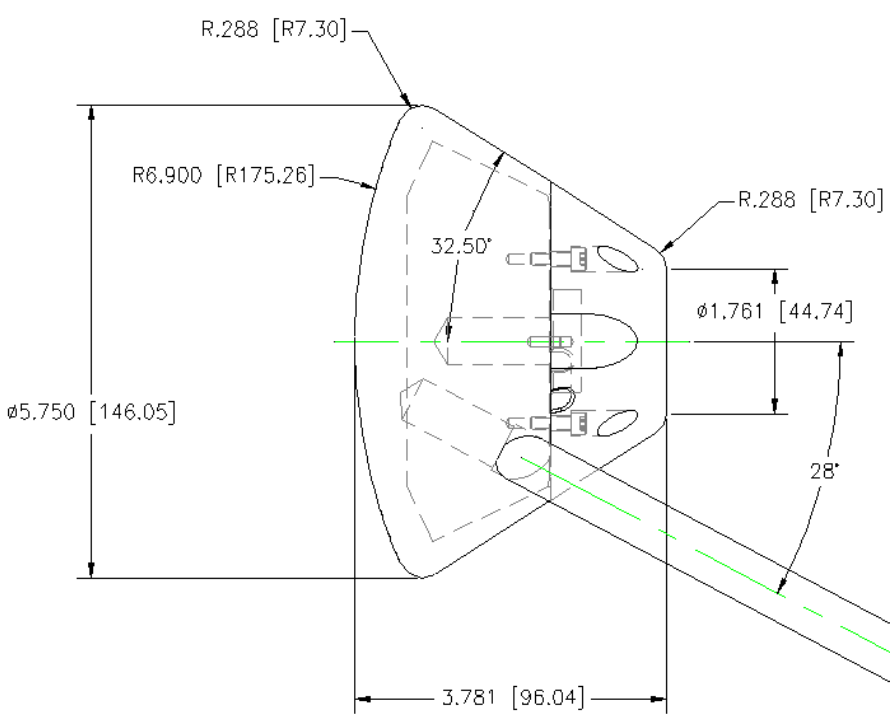

Figure 4. Dimensions of Generic Spherical Capsule Test Article (given in inches [mm])

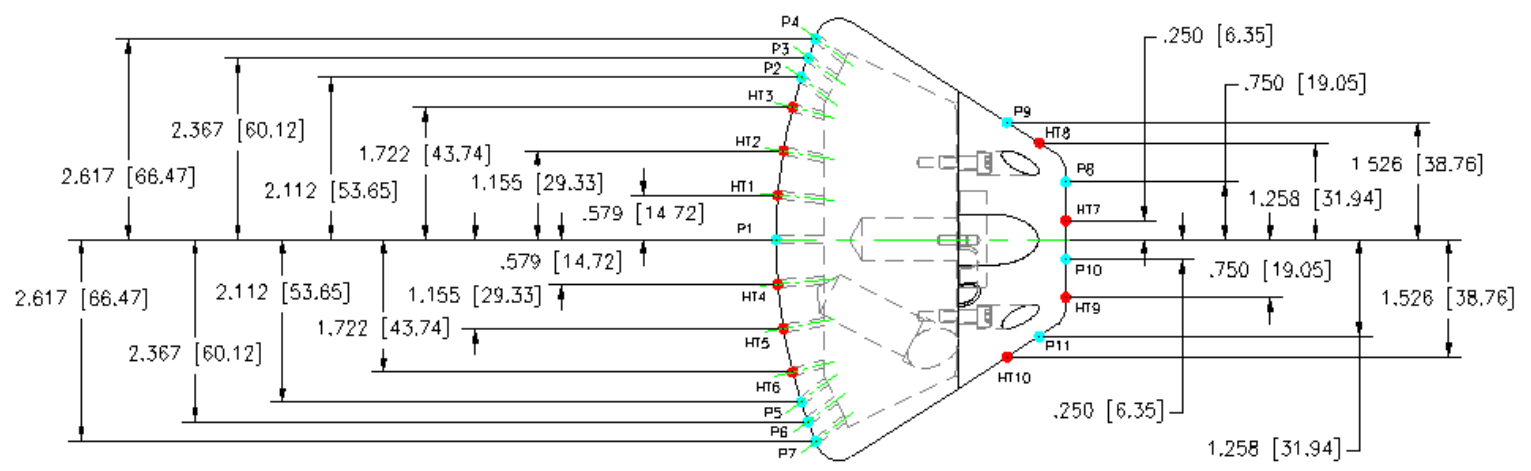

Figure 5. Instrumentation of Generic Spherical Capsule Test Article (given in inches [mm]) 
commercial, piezoelectric gages that have been based on an early Cornell Aeronautical Laboratory design. The gages are differential gages that measure pressure relative to the pretest baseline pressure level. Absolute pressures are computed by adding the measured baseline back in during the data reduction process. In addition, Schlieren was taken on every run and holographic interferometry was acquired for some runs.

The installed model in the facility is shown in Fig 6. Runs were made in the LENS-I facility at several enthalpy levels in both air and nitrogen test gases. The model was tested as part of a suite of diagnostics that also contained Pitot pressure, stagnation point and hemisphere probes, cone and static pressure probes, and laser-diode measurements. The capsule model, being a primary part of the test, sits approximately in the center of the test core just downstream of the exit plane of the nozzle. Approximately two dozen runs were made with this model installed in the facility, although some of the runs in the sequence were made for other purposes. A total of eleven unique runs were available with relevant data on the capsule.

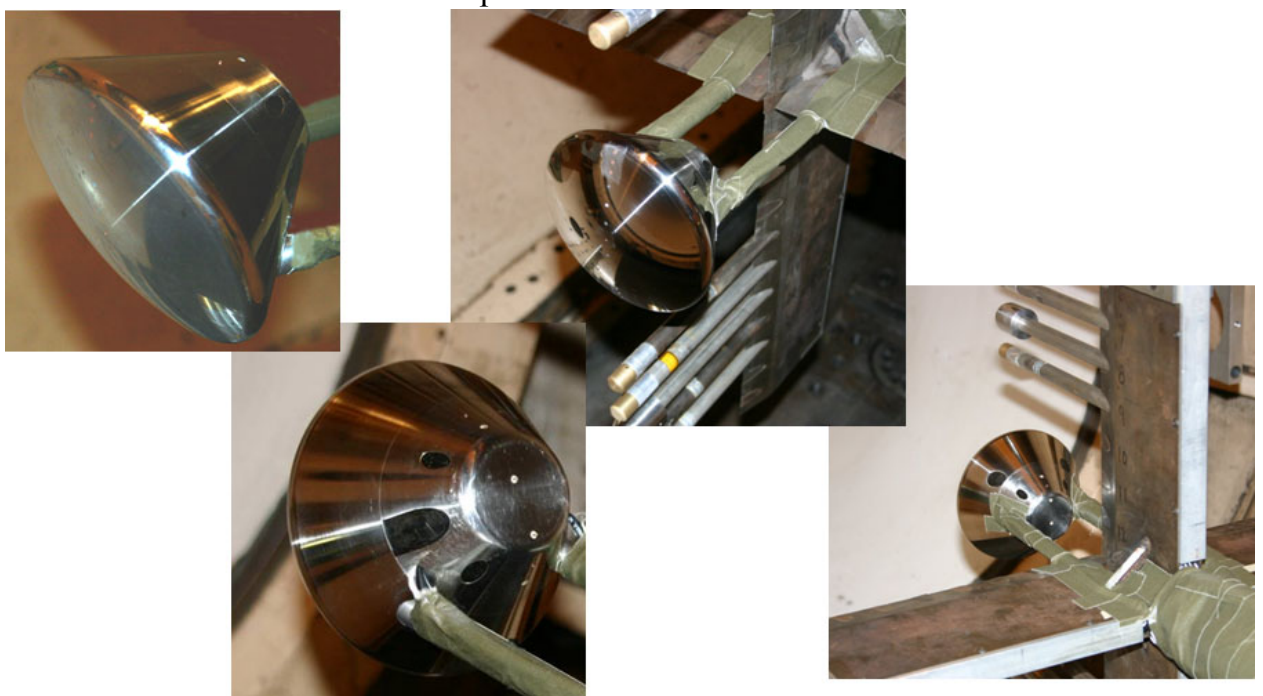

Figure 6. Generic Spherical Capsule Model Installed in LENS-I Facility

\section{Laminar Forebody Cases in Reacting Nitrogen}

Three runs were analyzed for which measurements on the capsule model were made in pure nitrogen as a test gas. The freestream conditions and angle of attack determined for these runs are given in Table 1. The freestream properties were determined using the Candler nozzle code by solving the nozzle flowfield and taking properties on the centerline of the nozzle near the installed location in the test section. In the case of pure nitrogen, vibrational relaxation is very slow and a very large vibrational energy remains frozen in the freestream as described by the single vibrational temperature. However, at moderate energy levels, the description of the vibrational activity of the gas using a single vibrational temperature (implying a simple harmonic oscillator with a Boltzmann distribution of vibrational states) has been found to be adequate on studies of the double cone geometry ${ }^{32}$ and analysis of the relaxation of nitrogen at higher energy levels in the facility nozzle did not indicate any significant non-Boltzmann behavior $^{29}$. Additionally, the runs were sufficiently energetic that a small amount of nitrogen atoms are formed. Readers intending to use these cases for code validation should note that even though the level of nitrogen atoms is small in comparison to the total density, the chemical enthalpy of nitrogen is so large that even these small levels are very significant and must be accounted for. Two angles of attack were studied at nominally $10 \mathrm{MJ} / \mathrm{kg}$. Run 18 was used to test tailoring in the facility by reducing the pressure ratio in the shocktube slightly. Even though it resulted in a total enthalpy that was about $90 \%$ of the two highest runs, Run 18 has less than half of the chemical dissociation in the freestream.

Table 1. Freestream Conditions for Laminar Runs in Pure $\mathbf{N}_{2}$

\begin{tabular}{c|c|c|c|c|c|c|c} 
Run \# & h0, MJ/kg & $\alpha$, deg. & $\mathrm{U}, \mathrm{m} / \mathrm{s}$ & $\mathrm{T}, \mathrm{K}$ & $\mathrm{T}_{\mathrm{V}}, \mathrm{K}$ & $\rho_{\mathrm{N} 2}, \mathrm{~kg} / \mathrm{m}^{3}$ & $\rho_{\mathrm{N}}, \mathrm{kg} / \mathrm{m}^{3}$ \\
\hline 13 & 10.4 & 28 & 4311 & 374 & 3272 & $1.322 \mathrm{E}-03$ & $7.794 \mathrm{E}-06$ \\
14 & 10.3 & 0 & 4279 & 369 & 3267 & $1.282 \mathrm{E}-03$ & $7.534 \mathrm{E}-06$ \\
18 & 9.0 & 0 & 4029 & 294 & 3032 & $1.431 \mathrm{E}-03$ & $3.076 \mathrm{E}-06$
\end{tabular}


The solutions to these cases were computed with a two species $\left(N_{2}, N\right)$, single reaction nitrogen model using several surface species boundary conditions. The non-catalytic surface boundary condition enforces zero gradients of species densities at the surface. Since large levels of chemical energy remains trapped by dissociated atoms, this boundary condition will always predict the lowest level of surface heating. The super-catalytic boundary condition enforces the chemical state that results in the minimum chemical energy. Since all available energy is returned to other modes of the gas, this boundary condition results in the prediction of the highest possible heat transfer rate to the surface. For the ground test facility with a constant $300 \mathrm{~K}$ wall temperature, the super-catalytic boundary is equivalent to enforcing local equilibrium on the gas. The super-catalytic model is non-physical in that it does not regard rate mechanics or elemental balance availability. The finite rate catalytic boundary condition ${ }^{33}$ balances the rate of production of a species with the rate of mass diffusing to the wall from the gas domain. Production rate is modeled with a first-order reaction rate that includes a recombination or atomic loss probability $(\gamma)$ that essentially specifies an efficiency with which atoms are converted back to molecules. The recombination probability can be specified in DPLR as a function of surface temperature, but, for the isothermal wall model of the ground test experiments, the probability is simply a constant value. In the specific case of $\mathrm{N}_{2}$, the finite catalytic wall considers only the single homogeneous reaction of atomic nitrogen recombining to form molecular nitrogen. There is no competition for available surface sites, heterogeneous reactions, etc. as in more complex scenarios.

Run 14 with a nominal total enthalpy of $10 \mathrm{MJ} / \mathrm{kg}$ is considered first. The predicted and measured heat transfer rates and pressure distribution are shown in Fig 7. The pressure distribution is well-characterized, which confirms that the number of molecules in the flow is correct. It also suggests that there are no significant flow gradients across this small capsule and justifies using the centerline values from the nozzle solution as a uniform freestream description. The heat transfer offers additional information. Considering only the non-catalytic and the supercatalytic solutions, which bound the possible heating values, the component of catalytic heating to the total is about $15 \%$. While not excessive, it is large enough to be significant. The measured heat transfer is significantly above the non-catalytic level and just below the super-catalytic level, which is at least "inbounds." The comparison was refined further by computing several finite rate solutions with different recombination probabilities, where a value near 0.0 implies little combination and a value near 1.0 implies significant recombination. The process is made

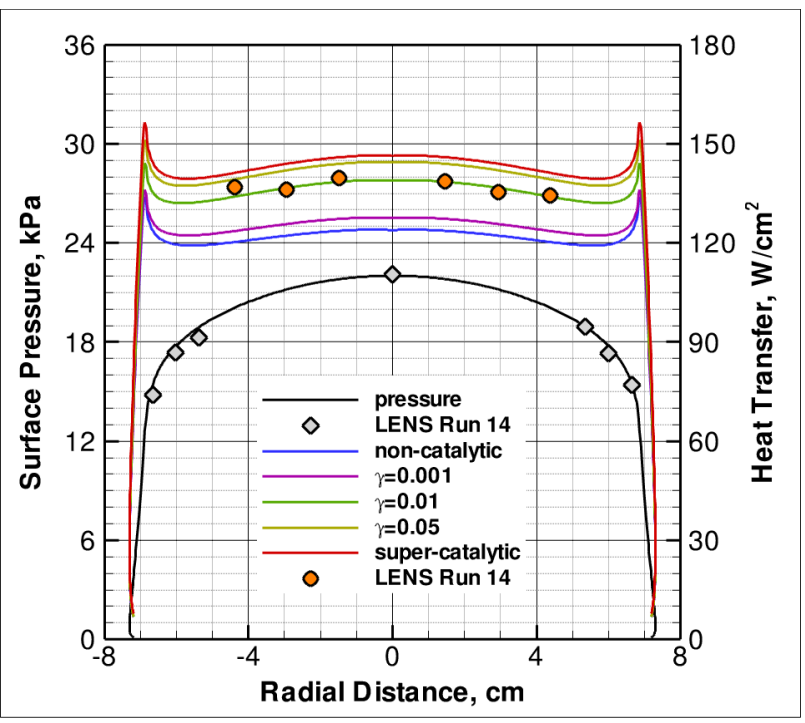

Figure 7. Comparison of Predicted and Measured Heat Flux with Several Surface Catalysis Models for Run $14\left(\mathrm{~N}_{2}, \mathrm{~h}_{0}=10.3 \mathrm{MJ} / \mathrm{kg}, \alpha=0^{\mathrm{O}}\right)$ nonlinear by the fact that the entire boundary layer is adjusting from case to case to accommodate the different surface boundary condition. A recombination probability of 0.01 best matches the measured data although a range about this mean is certainly feasible based on measurement uncertainty. That issue will be considered more carefully in a later section. Published values of nitrogen recombination efficiency on metallic surfaces vary wildly in the literature ${ }^{34}$, but values greater than 0.01 have been observed in other studies for cold wall stainless steel ${ }^{35}$.

Run 13 was made at the same nominal freestream conditions but at $28^{\circ}$ angle of attack. The comparisons of heat transfer and pressure between measurement and CFD are shown in Fig 8. Again, the pressure is accurately captured, with particular notice in the windward shoulder region where the gradient is very high. The bounding limits predicted between the non-catalytic and super-catalytic wall look smaller on the graphic, but the scale is much larger because of the larger heat transfer rates to the windward shoulder. The percentage of catalytic heating on the main body where the measurements are made is about the same as in the previous case $(\sim 15 \%)$. In this case, the heat transfer measurements correlate well with the non-catalytic prediction. The previously determined recombination probability value of 0.01 for the finite rate boundary condition is higher than the measured values, although it is not infeasible given the uncertainty in the measurements. Further testing of different recombination probabilities shows that a value of 0.002 is not significantly different than the non-catalytic level and it matches the mean measured points well.

Run 18, despite being close in total enthalpy to the two previous cases, shows considerably less dissociation both in the freestream and in the hot shock layer. The compared surface data is shown in Fig 9 for this case. In this case, 
the percentage of catalytic heating is about half of the previous cases $(<10 \%)$, which is consistent with the reduced dissociation observed in the flowfield. At less than $10 \%$, the catalytic behavior borders on insignificant. However, as the comparisons show, the experimental data does correlate quite well with the super-catalytic prediction of the CFD. A case with a finite rate boundary condition with a recombination probability of 0.01 (the value found for Run 14) is also consistent with the super-catalytic level and the measurements. Thus, saving a discussion of measurement uncertainty for a later section, we can conclude that a finite rate catalytic surface with a recombination probability in the range of 0.002 to 0.010 describes the available mean laminar data with the thermocouple style heat flux measurements for pure nitrogen flows with a single recombination mechanism.

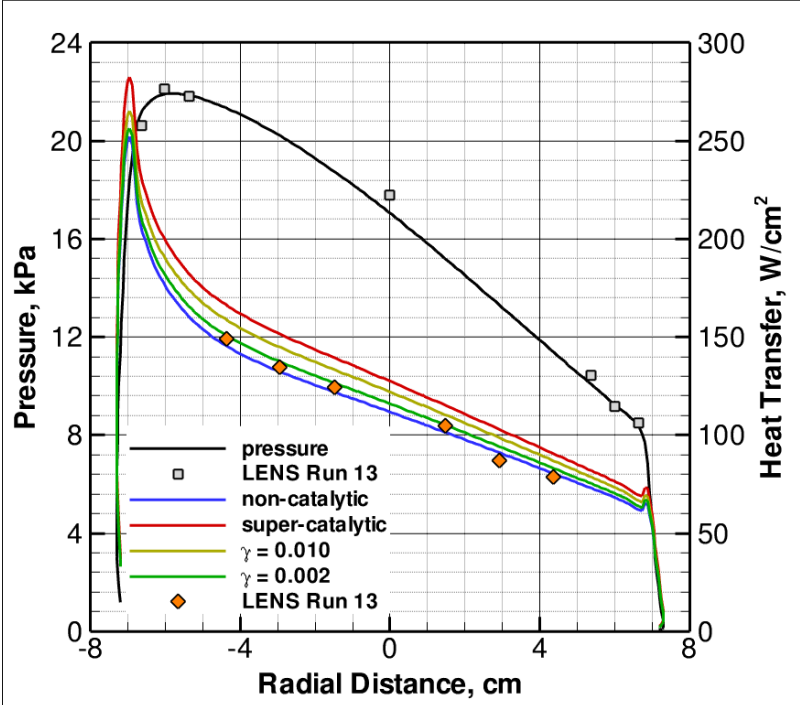

Figure 8. Comparison of Predicted and Measured Heat Flux with Several Surface Catalysis Models for Run $13\left(\mathrm{~N}_{2}, \mathrm{~h}_{0}=10.4 \mathrm{MJ} / \mathrm{kg}, \alpha=28^{\mathrm{O}}\right)$

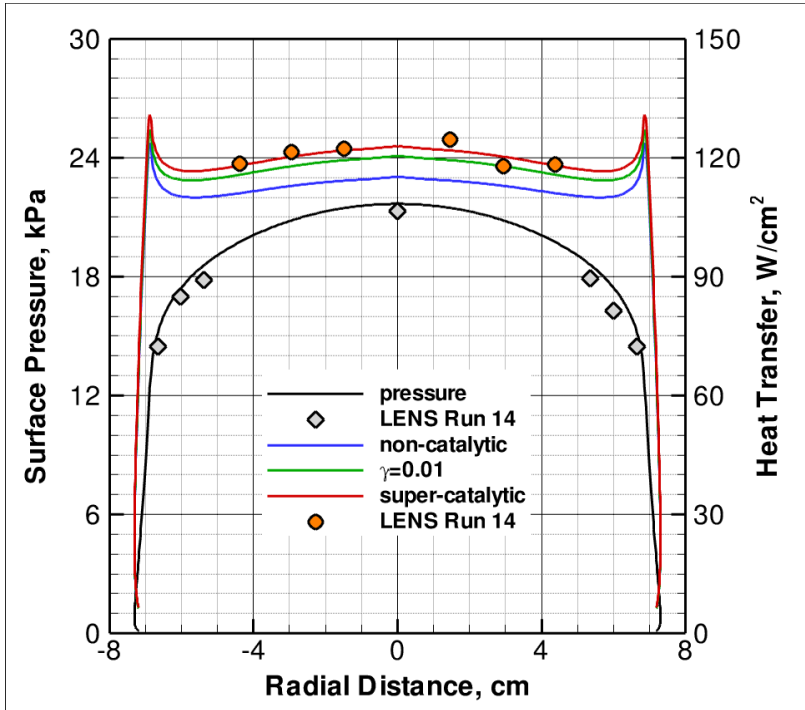

Figure 9. Comparison of Predicted and Measured Heat Flux with Several Surface Catalysis Models for Run $18\left(\mathrm{~N}_{2}, \mathrm{~h}_{0}=9.0 \mathrm{MJ} / \mathrm{kg}, \alpha=0^{\mathrm{O}}\right)$

Schlieren imagery is available from all three runs in this series and the images were compared to the CFD flowfield solutions for each run. This result is shown in Fig 10. In all cases, the predicted location of the shock from the CFD lines up with the Schlieren image so well that the CFD contour lines cover up the bow shock line in the Schlieren images. While the inaccuracy of lining up the two images provides only a first-order check of solution quality, it does verify that nothing is dramatically wrong with the simulation. Previous work on $\mathrm{CO}_{2}$ and some results in the next section show that if the freestream is sufficiently misrepresented, the CFD will predict too small a shock standoff distance.

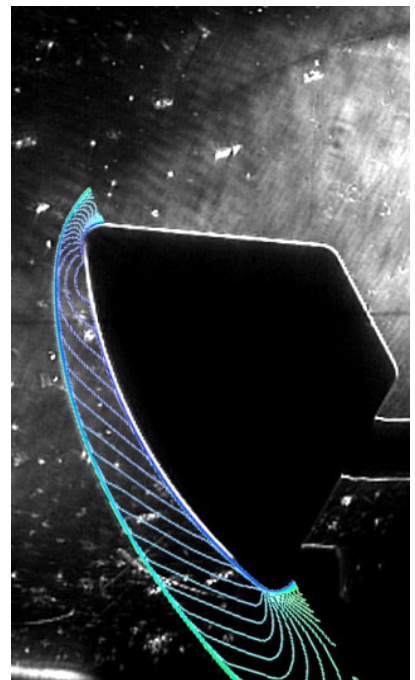

(a) Run $13, \mathrm{~h}_{0}=10.4 \mathrm{MJ} / \mathrm{kg}$

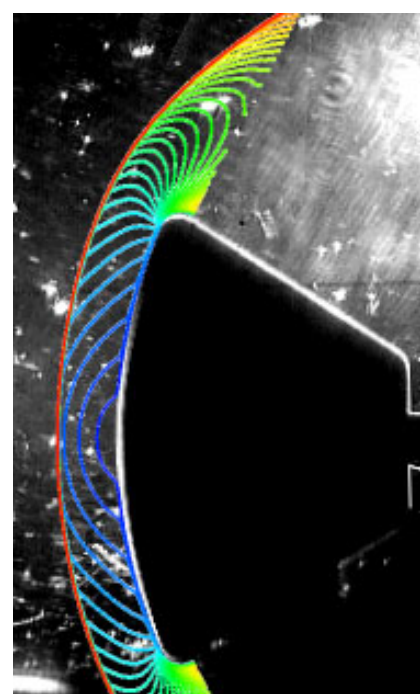

(b) Run $14, \mathrm{~h}_{0}=10.3 \mathrm{MJ} / \mathrm{kg}$

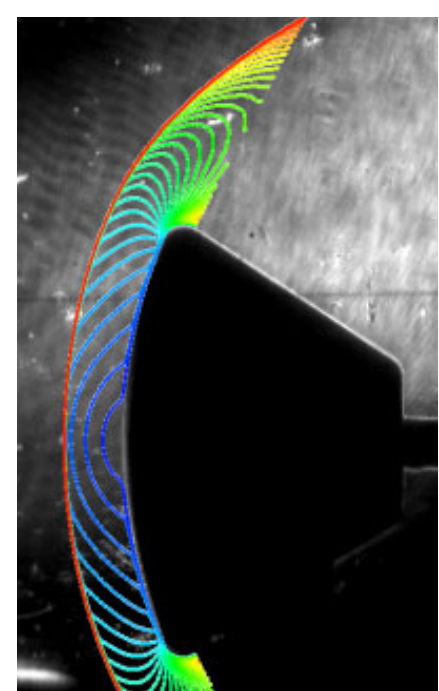

(c) Run $18, \mathrm{~h}_{0}=9.0 \mathrm{MJ} / \mathrm{kg}$

Figure 10. Comparison of Measured and Predicted Shock Shape for Three Runs in Pure $\mathbf{N}_{2}$ test Gas

7

American Institute of Aeronautics and Astronautics 


\section{Laminar Forebody Cases in Reacting Air}

A total of eight runs were made over a range of enthalpies with dry air as a test medium. Four runs were made at enthalpies of $2,5,10$, and $14 \mathrm{MJ} / \mathrm{kg}$ at $0^{\mathrm{O}}$ angle of attack and then these four runs were nominally repeated at $28^{\mathrm{O}}$ angle of attack. The air at the lowest enthalpy behaves as a perfect gas and it becomes increasingly reactive at the higher enthalpy conditions. The issue of vibrational non-equilibrium has been assessed previously ${ }^{2}$. While the rates according to Millikan and White ${ }^{11}$ seem to adequately describe the relaxation process in pure nitrogen, evidence exists that shows that the effective relaxation rate is very much faster when considering mixtures including oxygen $^{36}$. When these augmented rates ${ }^{13}$ are used to compute the nozzle flowfield, the vibrational temperature is predicted to be very close to the translational/rotational temperature. This is reflected in Table 2, which lists the conditions for all runs. Although a 5-species air model was used to solve both the nozzle and the capsule flowfields, the amount of atomic nitrogen in the freestream was predicted to be negligible in all cases because dissociated nitrogen more readily forms nitric oxide.

Table 2. Freestream Conditions for Laminar Runs in Dry Air

\begin{tabular}{c|c|c|c|c|c|c|c|c} 
Run \# & h0, MJ/kg & $\alpha$, deg. & $\mathrm{U}, \mathrm{m} / \mathrm{s}$ & \multicolumn{1}{c}{$\mathrm{T} \& \mathrm{~T}_{\mathrm{V}}, \mathrm{K}$} & $\rho_{\mathrm{N} 2}, \mathrm{~kg} / \mathrm{m}^{3}$ & $\rho_{\mathrm{O} 2}, \mathrm{~kg} / \mathrm{m}^{3}$ & $\rho_{\mathrm{NO}}, \mathrm{kg} / \mathrm{m}^{3}$ & $\rho_{\mathrm{O}}, \mathrm{kg} / \mathrm{m}^{3}$ \\
\hline 1 & 1.6 & 0 & 1832 & 57 & $6.005 \mathrm{E}-03$ & $1.845 \mathrm{E}-03$ & $0.000 \mathrm{E}+00$ & $0.000 \mathrm{E}+00$ \\
2 & 4.7 & 0 & 2922 & 180 & $2.264 \mathrm{E}-03$ & $6.097 \mathrm{E}-04$ & $2.143 \mathrm{E}-04$ & $1.505 \mathrm{E}-06$ \\
3 & 9.9 & 0 & 4167 & 522 & $1.168 \mathrm{E}-03$ & $2.719 \mathrm{E}-04$ & $1.041 \mathrm{E}-04$ & $4.596 \mathrm{E}-05$ \\
4 & 13.7 & 0 & 4772 & 646 & $7.470 \mathrm{E}-04$ & $1.208 \mathrm{E}-04$ & $5.534 \mathrm{E}-05$ & $8.692 \mathrm{E}-05$ \\
7 & 1.7 & 28 & 1805 & 57 & $6.978 \mathrm{E}-03$ & $2.144 \mathrm{E}-03$ & $0.000 \mathrm{E}+00$ & $0.000 \mathrm{E}+00$ \\
8 & 4.8 & 28 & 2949 & 191 & $2.431 \mathrm{E}-03$ & $6.529 \mathrm{E}-04$ & $2.339 \mathrm{E}-04$ & $1.902 \mathrm{E}-06$ \\
9 & 9.2 & 28 & 4054 & 494 & $1.214 \mathrm{E}-03$ & $3.035 \mathrm{E}-04$ & $9.108 \mathrm{E}-05$ & $3.402 \mathrm{E}-05$ \\
10 & 12.4 & 28 & 4601 & 631 & $7.937 \mathrm{E}-04$ & $1.493 \mathrm{E}-04$ & $6.347 \mathrm{E}-05$ & $6.949 \mathrm{E}-05$
\end{tabular}

The series at zero degrees angle of attack is considered first consisting of Runs 1 through 4.The comparison of predicted and measured heating for Run 1 is shown in Fig 11. The flow has a low enthalpy, so it behaves as a perfect gas with no chemical dissociation or vibrational excitation. Only one solution of heat transfer is given since there is no possibility of catalytic heating without dissociation in the shock layer. The comparison is good for both pressure and heat transfer.

The conditions for Run 2 are of a sufficiently high energy level that some dissociation occurs both in the freestream and subsequently in the shock layer. Peak temperature is about $4000 \mathrm{~K}$ in this flow. The comparisons with the surface measurements made for this run are shown in Fig 12. The surface pressure is as accurately predicted in this case as it was in the last one, but now two heating profiles are used to bound the surface heating prediction. As we have seen before in cases analyzed in reactive air and carbon dioxide flows, the super-catalytic model best describes the measured data despite the non-physical nature of

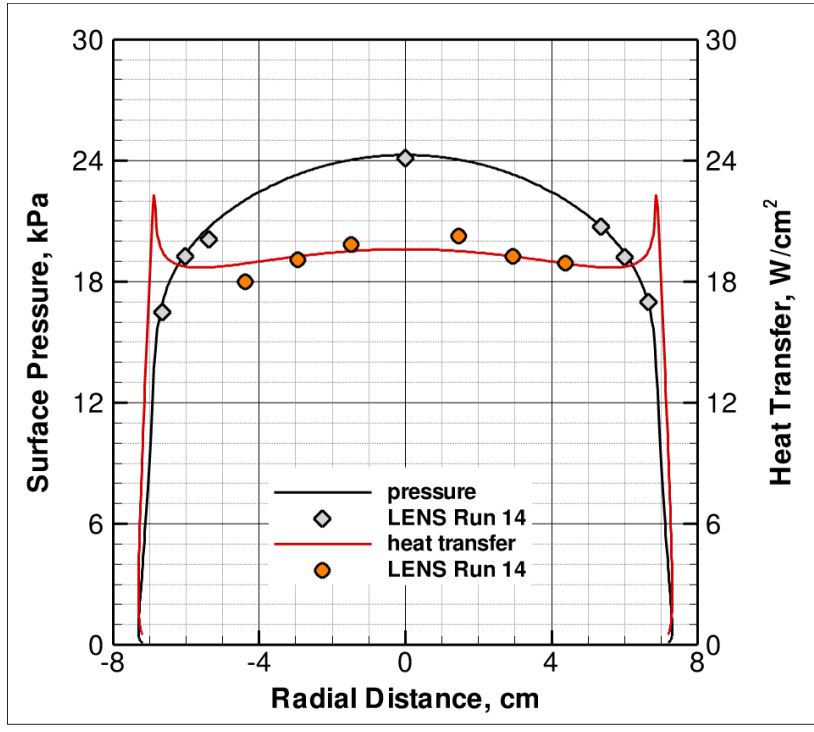

Figure 11. Comparison of Predicted and Measured Pressure and Heat Flux for Run 1 (Air, $h_{0}=1.6 \mathrm{MJ} / \mathrm{kg}$, $\alpha=0^{\mathrm{O}}$ )

the boundary condition. The percentage of catalytic heating is about $15 \%$ of the total for this case, so the discrepancy with the non-catalytic wall prediction is significant. A more detailed analysis of this case can be made by further considering the source of the catalytic heating. In this case, there is no atomic nitrogen present in the shock layer. All dissociated nitrogen is present as nitric oxide. Additionally, there is a significant amount of atomic 
oxygen present at the wall in the non-catalytic case. At the surface of the non-catalytic wall, the percentage of chemical energy is almost exactly equally divided between atomic oxygen and nitric oxide.

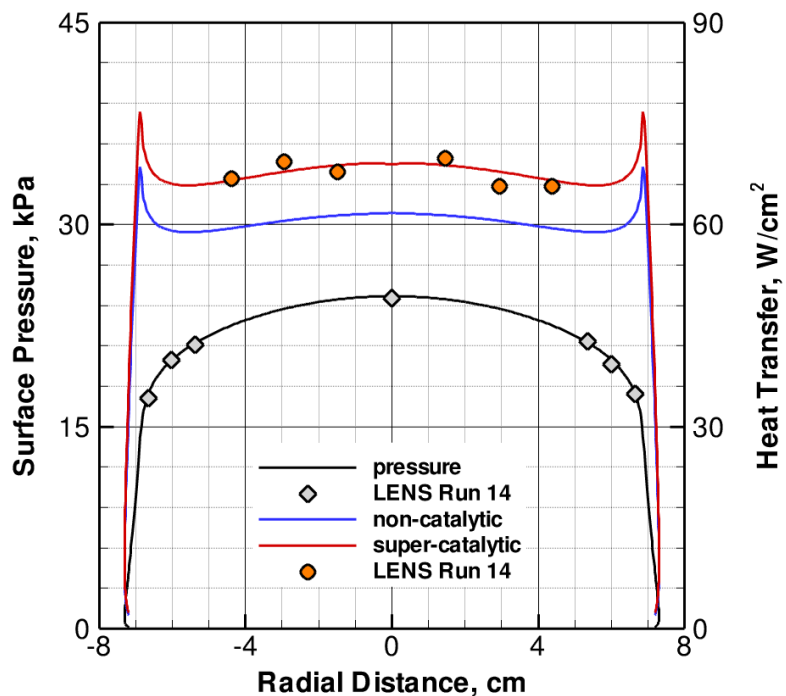

Figure 12. Comparison of Predicted and Measured Pressure and Heat Flux for Run 2 with Non-catalytic and Super-catalytic Walls (Air, $\mathrm{h}_{0}=4.7 \mathrm{MJ} / \mathrm{kg}, \alpha=0^{\circ}$ )

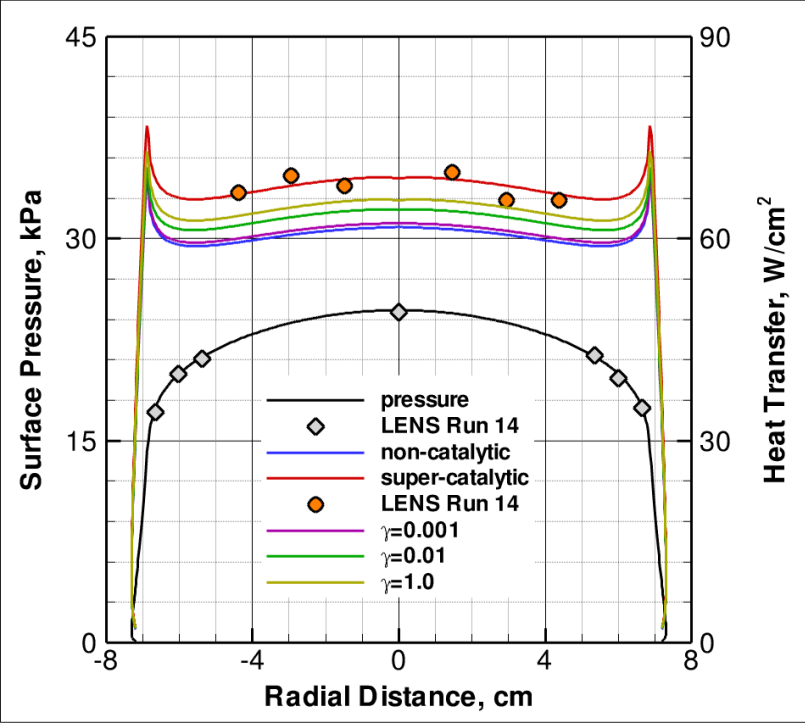

Figure 13. Comparison of Predicted and Measured Pressure and Heat Flux for Run 2 with Several Constant Efficiency Walls (Air, $h_{0}=4.7 \mathrm{MJ} / \mathrm{kg}, \alpha=0^{\circ}$ )

As shown in Fig 13, several finite rate cases were run using constant values of the recombination probability. For the finite-rate catalytic wall as implemented in the DPLR code, only the homogeneous recombination of atomic oxygen and atomic nitrogen (which is non-existent in this case) is modeled and the surface is assumed to be noncatalytic to nitric oxide. In this case as in the previous section, the solutions shown demonstrate the predicted effect of a single recombination mechanism on the surface. Several values are shown up to 1.0, which implies that every atom of oxygen diffused to the surface is transformed into molecular oxygen and its chemical energy recovered. The effect is somewhat non-linear since the near-wall profile of atomic oxygen in turn affects the near-wall profile of nitric oxide somewhat. However, at the maximum recombination efficiency of oxygen, the predicted heating is still smaller than five of six of the measured values and a significant gap between the $\gamma=1.0$ case and the supercatalytic case remains. This is the effect of the nitric oxide on the surface heating and the remaining discrepancy implies that nitric oxide must also be at least partially catalyzed by the surface ${ }^{37-39}$. Further, the very high efficiency of atomic oxygen seems unusual. As with the nitrogen recombination, the published recombination probabilities from the literature vary wildly. Atomic oxygen is in general understood to be more energetic than nitrogen. Values on the order of a significant fraction of 1.0 are sometimes quoted ${ }^{40-41}$, but this result seems to be very ideal for this surface. Since a significantly augmented level of surface reactivity is observed compared to the pure nitrogen cases, it may be a piece of evidence that suggests that energetic species resulting from the high temperature reservoir into the freestream may be a cause of the observed heating. The effect of electronic excitation in oxygen has been considered briefly before and was found to be negligible ${ }^{29}$, but further analysis along these lines may be warranted.

The compared surface heat transfer and pressure for Run 3 is shown in Fig 14. Here, the surface pressure seems to be well-captured as it was in the previous runs. However, unlike the previous case, the super-catalytic wall boundary condition does not describe the heat transfer measurements well. In this case, the measured heating pattern is about midway between the super-

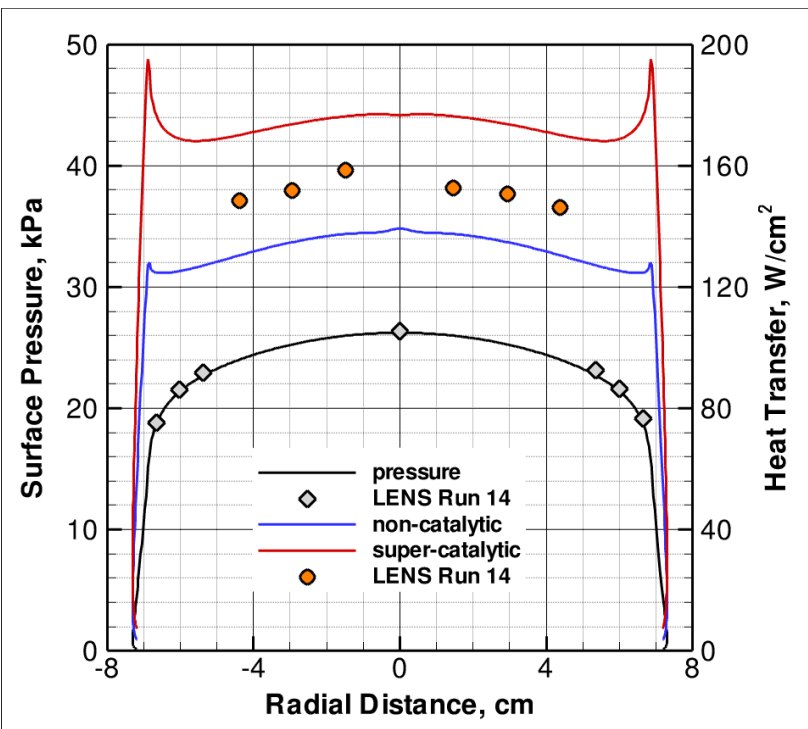

Figure 14. Comparison of Predicted and Measured Pressure and Heat Flux for Run 3 with Non-catalytic and Super-catalytic Walls (Air, $\mathrm{h}_{0}=9.9 \mathrm{MJ} / \mathrm{kg}, \alpha=0^{\circ}$ ) 
catalytic and non-catalytic solutions. Before further considering the implications of this result, it is necessary to consider the solution for Run 4 as well. This solution is shown in Fig 15. Here, the measured data lies far below even the non-catalytic heating prediction, which provides the lowest possible level heating that can be predicted with this set of physical models.

The most obvious source of error to consider is an error in the calculation of total enthalpy in the flow, which will be a first order influence on the predicted range of heat transfer. However, measurements of velocity using the Doppler shift technique with tunable diode laser absorption spectroscopy ${ }^{3}$ indicated that the velocity even at the highest enthalpy condition is accurately predicted to within a few percent. Since the kinetic component of the total enthalpy is the major contributor in the flowfield, the accuracy of the velocity implies that the total enthalpy of the facility cannot be sufficiently in error to account for the 50\% discrepancy observed for the heat transfer in Run 4. Additional insight can be obtained by looking at the comparison of the measured shock stand-off from the Schlieren system with the predictions for Runs 1 through 4. These comparisons are shown in Fig 16. For runs 1 and 2, the shock is as well-captured as it was for the nitrogen cases in the previous section. Starting with Run 3, however, differences between the measurement and the prediction are observed. For Run 3, these discrepancies are small, with the most significant differences observable at the

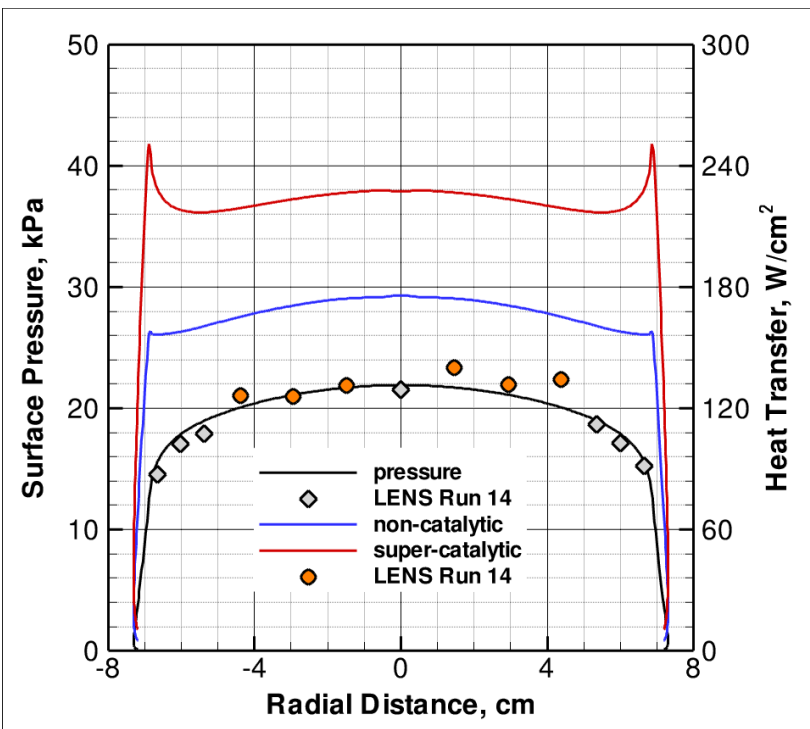

Figure 15. Comparison of Predicted and Measured Pressure and Heat Flux for Run 4 with Non-catalytic and Super-catalytic Walls (Air, $\mathrm{h}_{\mathbf{0}}=13.7 \mathrm{MJ} / \mathrm{kg}, \alpha=0^{\circ}$ ) nose and above the shoulders. For Run 4, the measured shock is significantly farther away than the prediction. In previous work analyzing $\mathrm{CO}_{2}$ test cases in the reflected shock tunnel facility, this same behavior was observed ${ }^{30}$. In that case as well, the shock stand-off was measured to be larger than predicted by a much more significant margin and the predicted heat transfer decreased significantly with increased shock stand-off distance. This behavior can be confirmed by considering the relationship expressed by Fay and Riddell ${ }^{42}$ which shows that larger shock stand-off distances (caused by larger nose radii in their analysis) results in a decrease in heat transfer. Thus, the larger measured shock stand-off would result in a smaller heat transfer to the body, which is consistent with the behavior for Runs 3 and 4 shown in Figs 14 and 15. Until the physical models of the CFD predictions can be modified to properly describe the behavior driving the stand-off distance of the shock, concluding anything about the relationship between the level of catalytic heating and the measurements for these two runs is impossible. However, it is possible to say that the predicted heat transfer range will decrease from the levels currently shown.

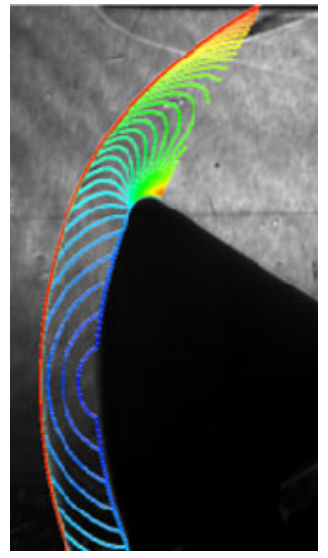

(a) Run 1, $\mathrm{h}_{0}=1.6 \mathrm{MJ} / \mathrm{kg}$

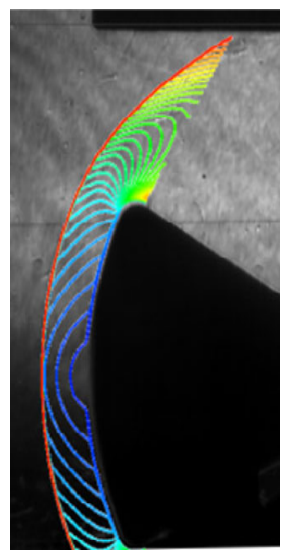

(b) Run 2, $\mathrm{h}_{0}=4.7 \mathrm{MJ} / \mathrm{kg}$

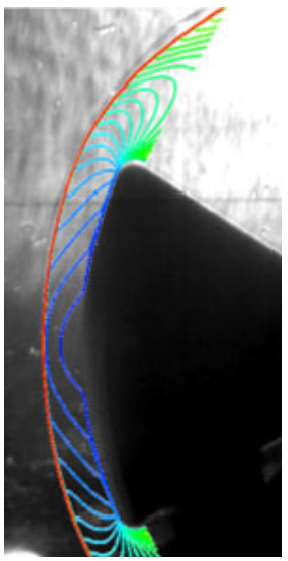

(c) Run 3, $\mathrm{h}_{0}=9.9 \mathrm{MJ} / \mathrm{kg}$

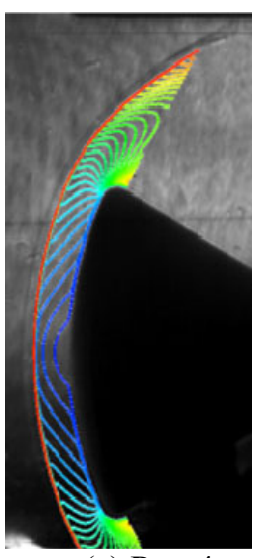

(c) Run 4, $\mathrm{h}_{0}=13.7 \mathrm{MJ} / \mathrm{kg}$

Figure 16. Comparison of Measured and Predicted Shock Shape for Runs 1 - 4 in Air Test Gas 
The series of solutions at $28^{\mathrm{O}}$ angle of attack over a similar enthalpy range is considered next. These conditions are also listed in Table 2. The conditions for this set of fours runs are nominally the same as the conditions for the set of four runs at zero degrees angle of attack. The CFD solutions for the surface pressure and heat transfer are compared to the measurements in Figs 17 through 20 for Runs 7, 8, 9, and 10 respectively. Many of the same observations made in the analysis of the previous set of runs can be seen in this set of comparisons as well. The lowest enthalpy case, Run 7, is generally well-predicted by the CFD as Fig 17 shows. Run 8 shown in Fig 18 demonstrates the effect of a small amount dissociation and thermal excitation and can be compared with the Run 2 results shown previously. As before at $5 \mathrm{MJ} / \mathrm{kg}$, the measured heat transfer lines up best with the super-catalytic boundary solution, confirming the result implying very efficient recombination of atomic oxygen and reclamation of nitric oxide. It is worth noting in this case that the scale on the heat transfer plot is, perhaps, somewhat misleading in that the difference between the non-catalytic and super-catalytic solutions looks to be insignificant. The difference due to catalytic heating along the central part of the body where the heat transfer gages are located is

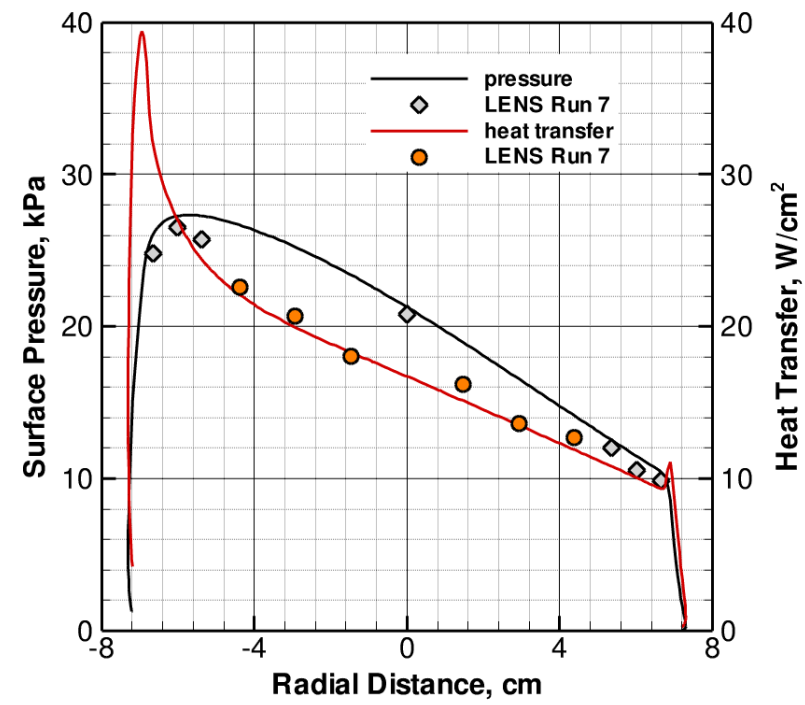

Figure 17. Comparison of Predicted and Measured Pressure and Heat Flux for Run 7 (Air, $\mathrm{h}_{0}=1.7 \mathrm{MJ} / \mathrm{kg}$, $\alpha=28^{\circ}$ )

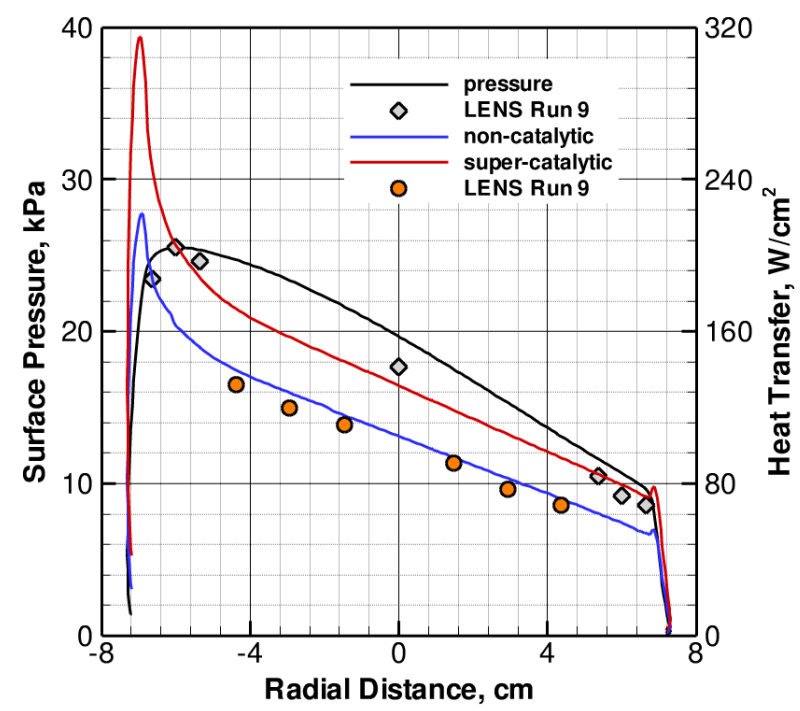

Figure 19. Comparison of Predicted and Measured Pressure and Heat Flux for Run 9 with Non-catalytic and Super-catalytic Walls (Air, $\mathrm{h}_{0}=9.2 \mathrm{MJ} / \mathrm{kg}, \alpha=28^{\circ}$ )

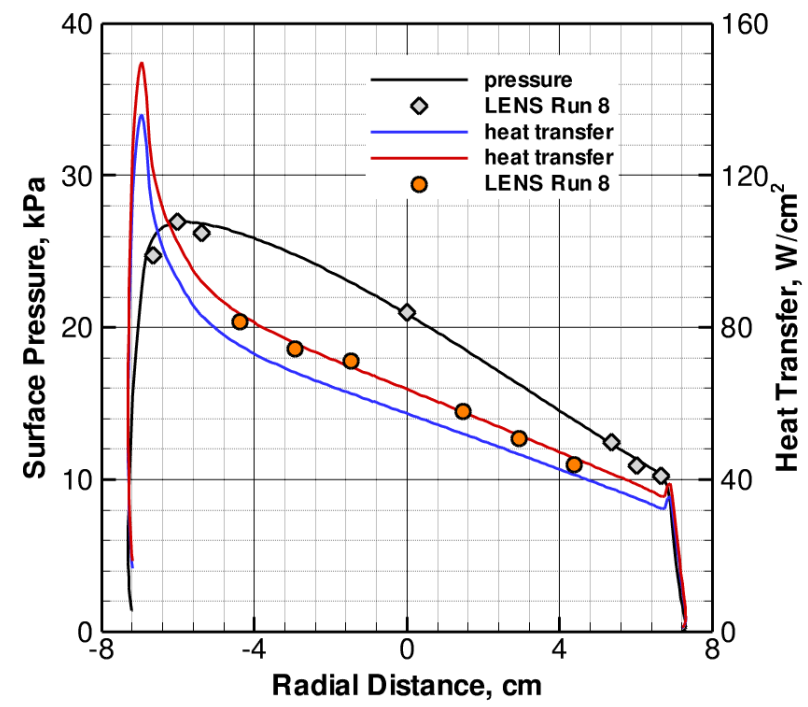

Figure 18. Comparison of Predicted and Measured Pressure and Heat Flux for Run 8 with Non-catalytic and Super-catalytic Walls (Air, $\mathrm{h}_{0}=4.8 \mathrm{MJ} / \mathrm{kg}, \alpha=28^{\circ}$ )

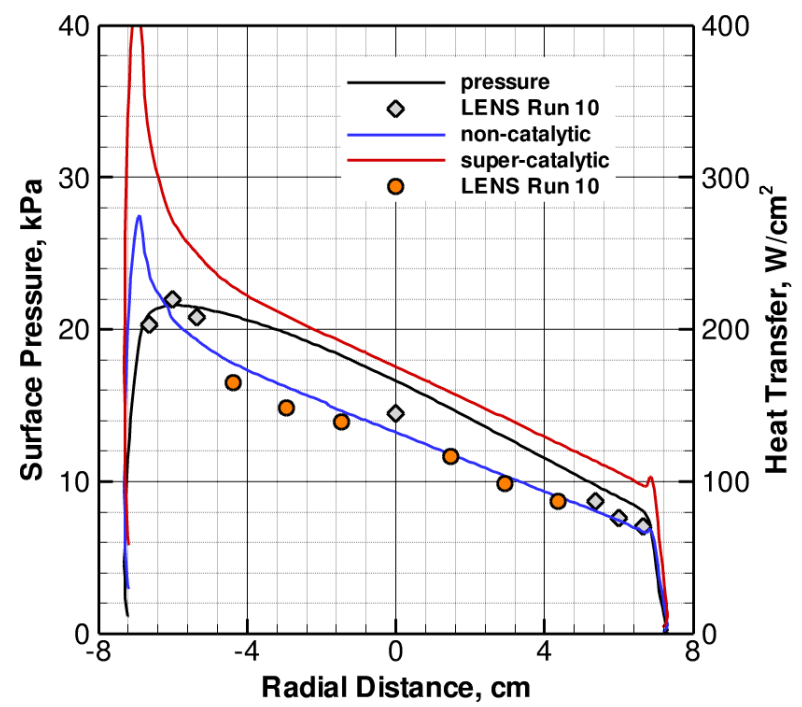

Figure 20. Comparison of Predicted and Measured Pressure and Heat Flux for Run 10 with Non-catalytic and Super-catalytic Walls (Air, $h_{0}=12.4 \mathrm{MJ} / \mathrm{kg}, \alpha=28^{\circ}$ ) 
actually about the same percentage of total heating as there was for Run 2 . The large scale necessitated by the comparatively high heat transfer to the windward shoulder makes the comparison seem less pronounced. No cases employing constant probability oxygen recombination have been shown for this case since that effect was already explored for Run 2 in Fig 13. Runs 9 and 10 shown in Figs 19 and 20 demonstrate the same behavior observed previously. The heat transfer measurements trend toward the non-catalytic solution. The comparison for Run 10 does not shown as large of a level of disagreement as was observed in Run 4, where the measured heat transfer was significantly smaller than even the non-catalytic solution predicted. However, Run 10 has a total enthalpy of 12.4 $\mathrm{MJ} / \mathrm{kg}$, while Run 4 has $13.7 \mathrm{MJ} / \mathrm{kg}$, implying that the observed discrepancy increases with increasing total enthalpy. Additionally, at $28^{\circ}$ angle of attack, the pressure distribution is sufficiently detailed to show discrepancy with the measured data for both Runs 9 and 10, particularly on the leeward side as the flow expands. The expansion on the front face of the capsule at $0^{\mathrm{O}}$ is small enough that this effect could not be discerned for those cases.

This discrepancy in the surface pressure distribution is directly attributable to misalignment of the shock between the prediction and experiment as shown in Fig 21. Here, as with the previous cases, the measured shock stands-off more at the highest enthalpies than the CFD predicts. Runs 7 and 8 capture the shock profile well, but Runs 9 and 10 show significant differences. The same argument can be made for these two cases as it was for Runs 3 and 4 , namely that the reduced heating observed from the measurements can be directly attributable to the shock standing off further from the body in the experiment. Therefore, for these runs as well, it is impossible to make a judgment about the contribution of catalytic heating to the model.

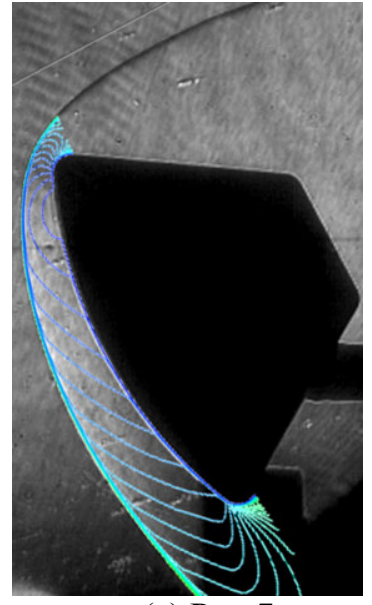

(a) Run 7 ,

$\mathrm{h}_{0}=1.6 \mathrm{MJ} / \mathrm{kg}$

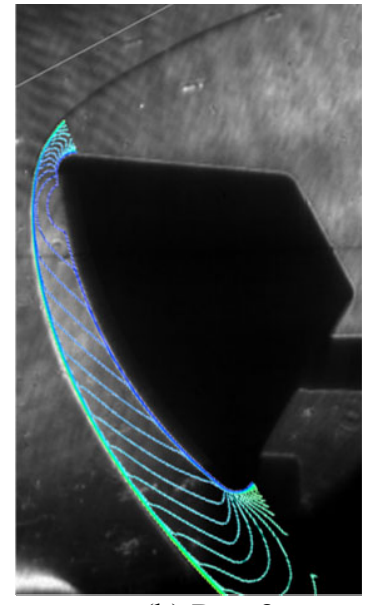

(b) Run 8 ,

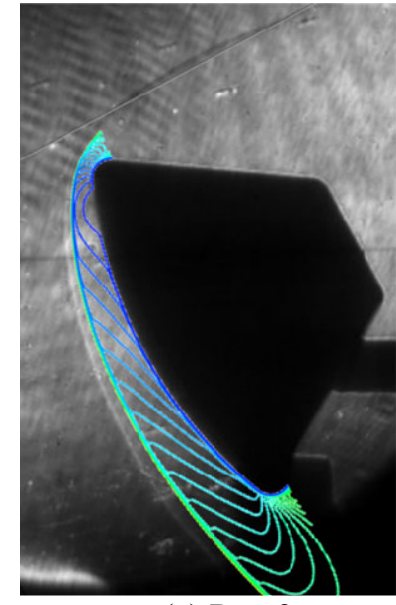

(c) Run 9, $\mathrm{h}_{0}=9.2 \mathrm{MJ} / \mathrm{kg}$

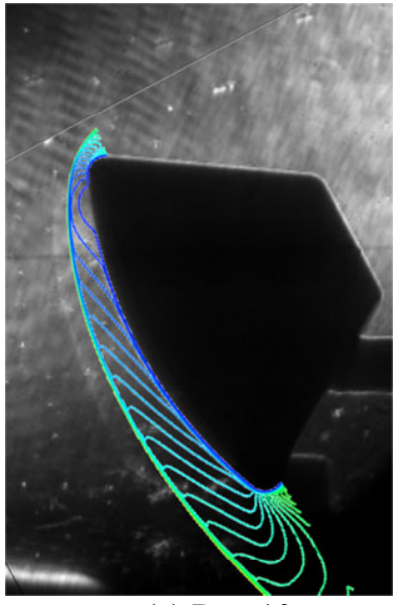

(c) Run 10, $\mathrm{h}_{0}=12.4 \mathrm{MJ} / \mathrm{kg}$

Figure 21. Comparison of Measured and Predicted Shock Shape for Runs 7 - 10 in Air Test Gas

\section{Discussion}

\section{A. Uncertainty Analysis}

The issue of uncertainty in the measurements is briefly considered with respect to the surface catalysis issue. In the cases considered in both air and nitrogen, the tentative conclusions made about the recombination probability of the associated catalytic processes on the surface of the model depend heavily on understanding the accuracy of the measurements. Especially in the cases with the nitrogen gas, the difference between the non-catalytic level and the super-catalytic level is small enough that the significance of the comparisons is a concern. To understand this component of the analysis, Run 13 was selected and the heat transfer time history traces were reviewed in detail. During the window of test time for which the average heating measurement of the six heat flux gages is shown in Fig 8 , the statistical properties of the measurements were extracted. The standard deviation was computed and used as a metric of uncertainty.

The comparisons of the measurements with the CFD solutions are repeated in Fig 22 showing the average measurements with one standard deviation and two standard deviations of error bars on each point. One standard deviation represents a $68 \%$ confidence interval in the data. Two standard deviations represent a $95 \%$ confidence interval in the data. The CFD solutions represent the bounds of recombination probability estimated from the mean data for the three runs as well as the limiting non-catalytic and super-catalytic trends. The recombination probability of 0.002 was picked as a best fit for this particular run. The upper bound predicted from the previous analysis of 
0.010 is also shown for this case. As discussed previously, for five out of six points, the 0.002 solution matches the data within one standard deviation of uncertainty.

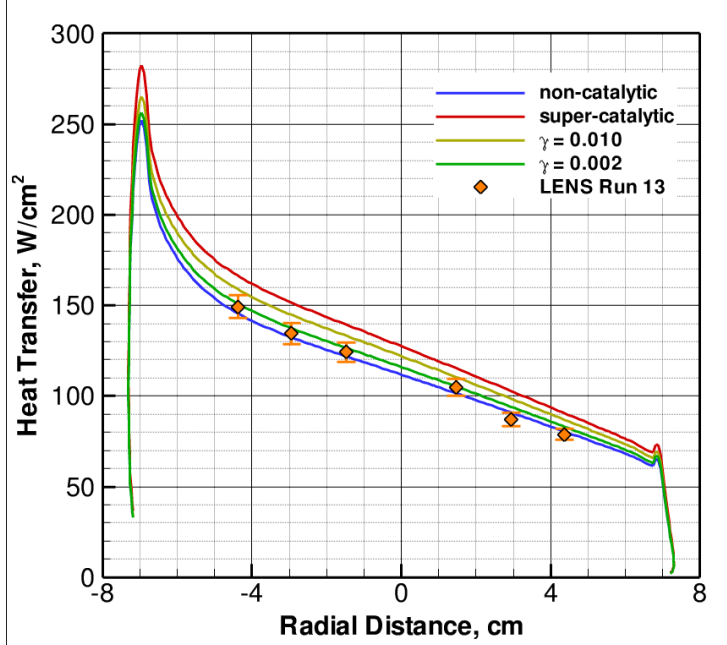

(a) 1-Sigma Error Bars

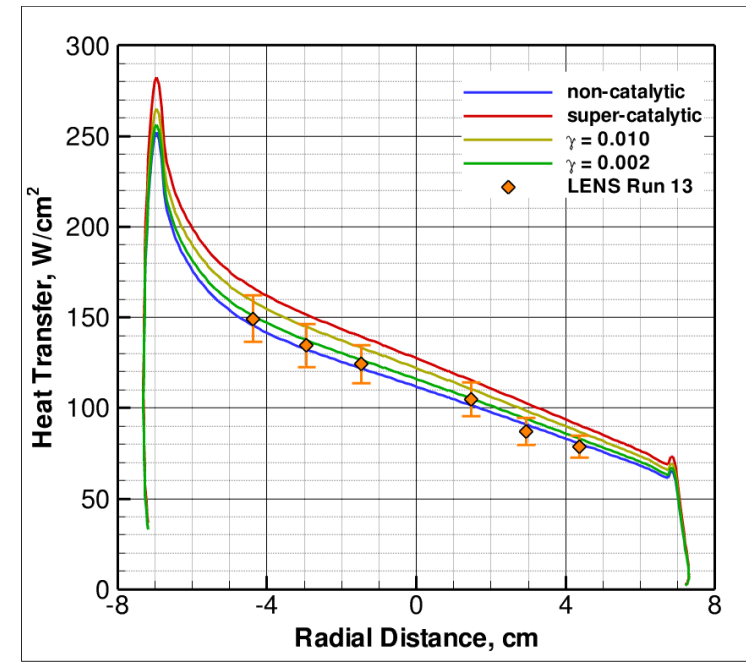

(b) 2-Sigma Error Bars

Figure 22. Comparison of CFD Solutions with Measurements for Run 13 Showing Standard Deviation Based Error Bars

The important result is that the data is not described by the super-catalytic solution with a $95 \%$ confidence. It is also useful to note that the non-catalytic surface boundary condition may be thought of as simply a surface with an infinitely small recombination probability and that even moderate recombination probability values $(<0.001)$ produce results that are very consistent with the non-catalytic solution. With $95 \%$ confidence, we can conclude that the behavior of the stainless steel surface is described by a model of constant recombination probability somewhere between $10^{-3}$ and $10^{-2}$ accounting for the uncertainty in the measurements. It is not possible to reduce the range of possible levels of catalytic activity with additional surety in this case since the measurements to three standard deviations of uncertainty encompasses the entire range of possible solutions. However, while it is not possible to derive any definitive conclusions, a $95 \%$ confidence is sufficient to suggest a direction of future exploration in these types of flows.

\section{B. Effect of Thermochemical Non-equilibrium on Capsule Stability}

The effect of thermochemical non-equilibrium on the predicted and measured stability of the capsule was considered with this dataset by computing the change in pressure across the forebody of the capsule at $28^{\mathrm{O}}$ angle of attack over a range of freestream velocity (total enthalpy) values. For the experiments, this effect was computed by taking the difference between the measured pressures P3 and P6 (Fig 5) and normalizing it by the Pitot pressure measured from Pitot probes adjacent to the capsule model. The CFD solutions were used in the same way by extracting surface pressures at those two matching locations and computing the same normalized parameter for each case. Such a parameter is one metric of pitching moment for the capsule vehicle.

The results comparing experiment to CFD is shown in Fig 23. The perfect gas result is a constant taken from the lowest enthalpy solution of the CFD and remains constant at any freestream enthalpy since perfect gas assumptions imply no modeling of vibration or chemical dissociation. The inclusion of these effects changes the pressure distribution on the capsule significantly as shown. Since the results in the previous section showed that the CFD solution

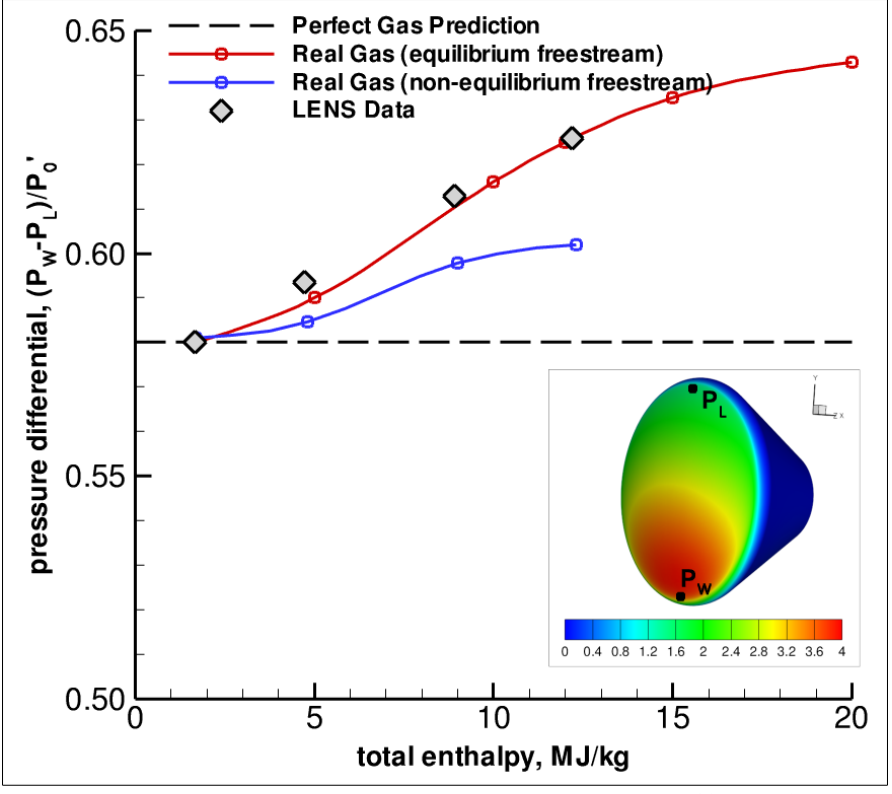

Figure 23. Predicted and Measured Effect of Thermochemical Non-equilibrium on Capsule Stability 15

American Institute of Aeronautics and Astronautics 
did not match the pressure distributions measured very well, two sets of simulations are shown. The first set is the trendline of the non-equilibrium solutions from Runs 7, 8, 9, and 10 using the freestream conditions in Table 2. These are the solutions shown already in Figs $17-20$. The second set of solutions assumes purely equilibrium freestream conditions, but models the non-equilibrium in the shock layer. This would correspond to the prediction of a flight case at that enthalpy.

The experimental data and both the equilibrium and non-equilibrium freestream solutions show that the perfect gas result significantly under-predicts the pressure gradient at high enthalpy. However, the most surprising result is that the data seems to match up with the equilibrium freestream solution trend with uncanny accuracy. This was an unexpected result. The modeling of the CFD to predict the freestream state of the gas was obviously unsuccessful in comparing to the surface pressure distribution over the capsule with those freestream conditions. The discrepancy with the data obviously became greater as the enthalpy increased, but the detailed analysis of the surface data seemed to suggest that the freestream was in a non-equilibrium state that the CFD could not adequately describe. The reason why the surface pressure so closely resembles the result predicted for an equilibrium freestream state is a mystery, but it does seem clear that a better physical model describing the thermochemical behavior of this gas (both in the expanding nozzle flow and the shock layer flow) is needed.

\section{Effect of Vibrational Relaxation on Shock Stand-off}

One effect that has been considered in the analysis of the high enthalpy laminar data is the effect of the assumption that the vibrational relaxation in air occurs much more quickly than the relaxation in pure nitrogen. The modeling of the nozzle expansion with the specialty code and the shock layer flow with DPLR was done using augmented vibrational relaxation rates which come from available data ${ }^{13}$. Previous modeling of high enthalpy flows at 5 and $10 \mathrm{MJ} / \mathrm{kg}$ in LENS-I indicated that the fast relaxation rates better described the freestream test core ${ }^{2}$. When compared to rakes of Pitot pressure measurements, the augmented rates reproduced the profile accurately while the Millikan-White rates did not. However, given the differences observed in the prediction of shock stand-off in a few of the highest enthalpy cases, this conclusion has been revisited to assess whether modeling the flow with the much slower Millikan-White rates can improve the prediction of the shock profile on the model at all. Run 9 was selected as the candidate case to test this effect. The original set of conditions is given in Table 2 for this run. A second case was computed using the nozzle code with Millikan-White rates and the following set of freestream conditions was obtained: $\rho_{\mathrm{N} 2}=1.26 \times 10^{-3} \mathrm{~kg} / \mathrm{m}^{3}$, $\rho_{\mathrm{O} 2}=3.15 \times 10^{-4} \mathrm{~kg} / \mathrm{m}^{3}, \rho_{\mathrm{NO}}=9.44 \times 10^{-5} \mathrm{~kg} / \mathrm{m}^{3}, \rho_{\mathrm{O}}=3.52 \times 10^{-5}$ $\mathrm{kg} / \mathrm{m}^{3}, \mathrm{U}=4017 \mathrm{~m} / \mathrm{s}, \mathrm{T}=396 \mathrm{~K}, \mathrm{~T}_{\mathrm{V}}=2123 \mathrm{~K}$. The DPLR code was then also run with the Millikan-White rates controlling the vibrational relaxation source term and the shock layer flow was recomputed to be consistent.

The comparison showing the symmetry plane shock position for these two flows is given in Fig 24. The result shows that the shock is computed to be in approximately the same location for both methods. This result makes sense because the slower rates affect the rate at which the vibrational mode relaxes both on the outside and the inside of the shock simultaneously. The net effect is that there is little change to the position. This is confirmed by the comparison of the pressure distribution predicted by the two methods shown in Fig 25. The two solutions collapse exactly. Therefore, one can conclude that the simple mechanism of vibrational relaxation rate is not to blame for the problem predicting the shock position.

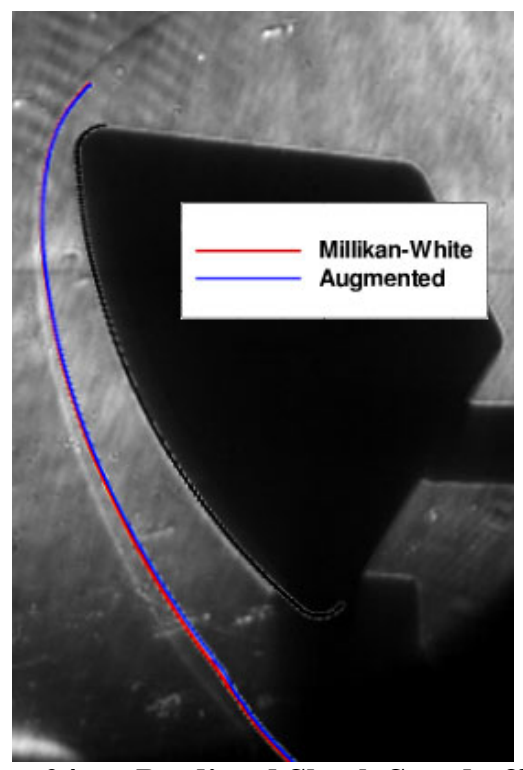

Figure 24. Predicted Shock Stand-off and Profile for Run 9 using Millikan-White and Augmented Vibrational Relaxation Rates

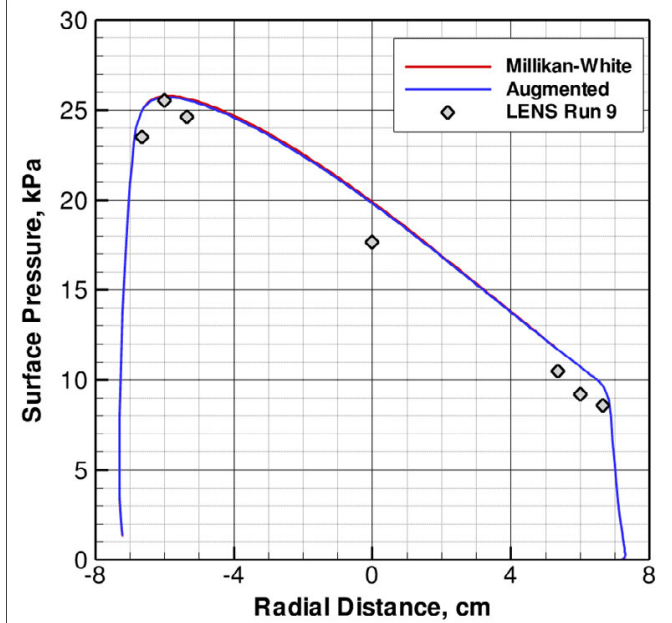

Figure 25. Predicted Surface Pressure for Run 9 using Millikan-White and Augmented Vibrational Relaxation Rates 


\section{Effect of Pressure on Surface Properties and Shock Stand-off}

Additional understanding of the thermochemical non-equilibrium and catalytic heating issues observed in this test series may be obtained by comparing the results shown in the previous sections with a comparison to a single run from the Orion CEV/CRV 67-CH test program. The primary objectives of the 67-CH program were to make detailed measurements of heat transfer distributions through the windward shoulder region of the Orion capsule at angle of attack in order to understand the processes of transition, turbulence, and potential re-laminarization in the expanding flow around the shoulder that would impact the TPS design requirements in that region. The model tested for $67-\mathrm{CH}$ is a $7.0 \%$ scale model of the Orion vehicle OML constructed of stainless steel with a mix of thinfilm and thermocouple heat flux gages along the symmetry plane of the model including both windward and leeward shoulder regions. While larger in size than the generic capsule model studied in this work, the forebody of both models are geometrically similar. Details of this test series are scheduled for future publication ${ }^{43}$.

The bulk of the runs made in this test program were done at low enthalpy conditions to maximize the Reynolds number space of the test. At such cold conditions, Reynolds number based on diameter of up to $37 \times 10^{6}$ was tested. As a secondary objective in $67-\mathrm{CH}$, several runs were made at higher enthalpies to assess the impact of flow velocity on the transition process in the shoulder region. As part of this secondary effort, a single run is available with laminar flow over the forebody of the vehicle at a total enthalpy of $10.27 \mathrm{MJ} / \mathrm{kg}$ in dry air at $20^{\circ}$ angle of attack. This condition matches very closely to Runs 3 and 9 studied here. The main difference of interest is that in the $67-\mathrm{CH}$ run, the Reynolds number per meter in the freestream was $1.40 \times 10^{6} / \mathrm{m}$ while Runs 3 and 9 had $2.27 \times 10^{5}$ $/ \mathrm{m}$ and $2.38 \times 10^{5} / \mathrm{m}$ respectively. The fivefold difference in Reynolds number is proportional to the total pressure selected for the facility based on the program needs. Total pressure in a reflected shock tunnel is controlled by raising the pressures in both driver and driven tubes equally, so the gasdynamics and tailoring of the facility remains identical. Therefore, the 67-CH case demonstrates the effect of having about five times the density of molecules, and more importantly molecular collisions, during the expansion process from reservoir to freestream states.

The comparison of the predicted and measured shock shape on the model is shown in Fig 26. The Schlieren was set up to meet other program objectives for 67-CH so only part of the forebody is visible. Additionally, since the system was best calibrated for the low energy cases that comprised the bulk of the effort, there is a high level of background light from the energetic shock layer that makes the model surface during the test difficult to pick out. The pre-run (tare) image shown was used to properly line up the CFD solution to the model as the images from the high speed camera are spatially consistent from frame to frame. The portion of the forebody that is available for comparison shows that the measured shock position and the CFD prediction line up exactly. This is unlike the cases shown in the previous sections where the CFD solution with the same thermochemical models under-predicts the shock stand-off distance at this enthalpy level but at much lower freestream densities.

The comparison of the measured heat transfer with a mixture of thin-film and thermocouple gages to the predicted heat rates with non-catalytic and super-catalytic wall boundaries are shown in Fig 27. The first point is that the predicted gap between the catalytic and non-catalytic heating level predictions is much smaller for this case due primarily to the larger flow pressure in the shock layer that increases the chemical kinetic recombination rates as

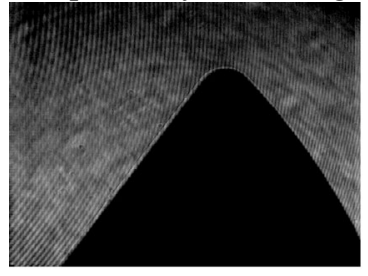

Prerun (Tare) Image

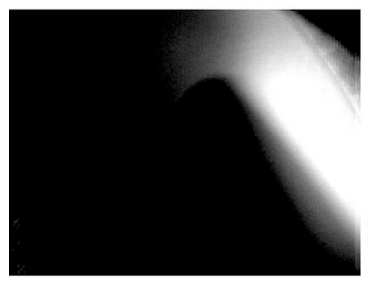

Flow Image

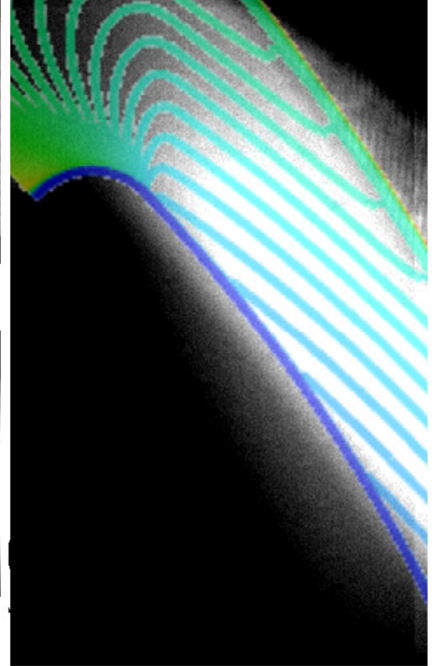

Figure 26. Comparison of Measured to Predicted Shock Shape on Orion Capsule at 10.27 MJ/kg and $1.4 \times 10^{6} / \mathrm{m}$

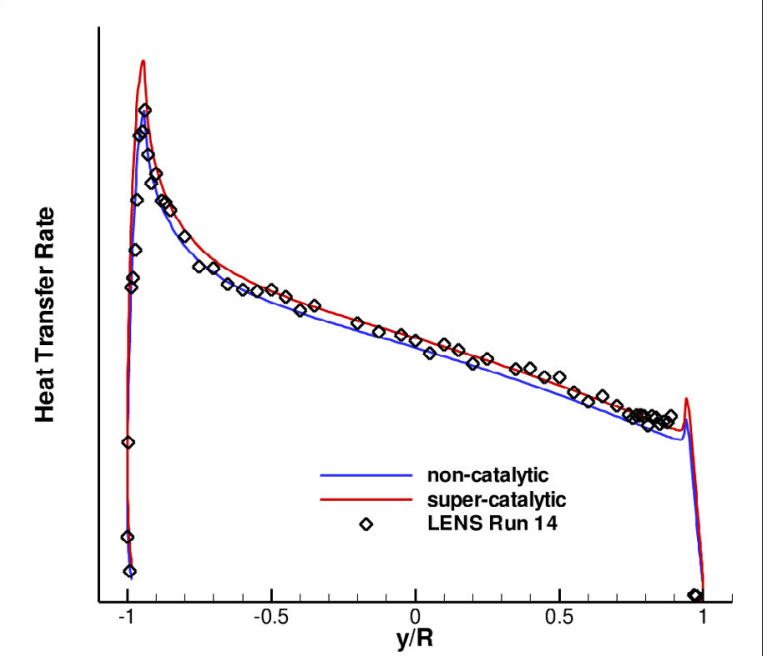

Figure 27. Comparison of Measured and Predicted Heat Flux Levels on Orion Capsule at 10.27 MJ/kg and $1.4 \times 10^{6} / \mathrm{m}$

15

American Institute of Aeronautics and Astronautics 
the flow adapts to the cold wall. Over the bulk of the forebody the difference between the two predicted levels is only $4 \%$. The measured heat transfer rates fall within this very narrow range with uncanny precision. Even at the peak heating point on the windward shoulder, the difference between the two predicted levels is only $10 \%$ which is marginally significant in terms of the measurement accuracy. The gradient in this region is also very steep so that a small shift in radial position can change the heating level far more than this. However, in this region, the heating profile does seem to match up best with the non-catalytic solution. The very limited evidence is not strong enough to draw a definitive conclusion, but it does suggest that at the higher pressure condition the catalytic recombination probability may be tending to drop to lower levels much more in line with the expected behavior for stainless steel.

Although very limited in scope and quantity, this evidence presented from this $67-\mathrm{CH}$ run, when contrasted with runs at similar enthalpy levels but at much lower pressures, may suggest that molecular collision limited nonequilibrium phenomena may be the cause of the inability of the CFD to predict the state of the flow for $10 \mathrm{MJ} / \mathrm{kg}$ flows and above when they are expanded from a stagnant reservoir.

\section{Conclusions/Comments}

A dataset has been generated on a 146-mm diameter spherical capsule to study the fundamental phenomena associated with testing Apollo and Orion vehicle geometries at relevant high enthalpy conditions in the LENS-I reflected shock tunnel facility. The test program consisted of a series of runs at $0^{\circ}$ and $28^{\circ}$ angle of attack for a range of total enthalpy in air and nitrogen test gases. Measurements were made of surface pressure, surface heat transfer, shock shape, and interferometry on the capsule forebody. These results have been shown for three cases in nitrogen and eight cases in air.

In nitrogen flow, the CFD was shown to be capable of predicting all of the quantities measured in the experiment with good accuracy. Of primary interest is that at high enthalpies, the heating measured on the forebody was estimated to be most consistent with a range of recombination efficiency of 0.002 to 0.010 . Although some uncertainty remains in this estimate, the range is consistent with published values for nitrogen recombination.

In air, there were several indications that the flow was sufficiently more energetic. At moderate enthalpy, the flow was found to corroborate best with the super-catalytic boundary condition. This implies that the recombination efficiency for both atomic oxygen and nitric oxide is approximately 1.0. At higher enthalpies, it was shown that the shock stand-off distance was not well-predicted with the set of freestream conditions generated by computing the flowfield of the expanding nozzle with a single vibrational rate equation and five species air chemistry. This may imply additional non-equilibrium processes are important that are not modeled with this thermochemical description. Energetic states may also be important in the catalytic recombination processes occurring on the surface of the capsule model. Limited results of available comparisons have indicated that the non-equilibrium phenomena involved mitigate as pressure in the facility increases. This may suggest that collision limited phenomena are dominating the state of the freestream flowfield such that higher pressure in the nozzle results in more collisions and a freestream test state that is closer to equilibrium.

The most surprising finding in this study was that the pressure gradient on the forebody of the capsule compares very favorably to the CFD solution obtained using an equilibrium flowfield despite the contradictory findings that the freestream contains non-equilibrium energy. The reason for this agreement is unknown.

The purpose of this study has been to explore some of the phenomena associated with the study of a capsule under reentry conditions for future application to Orion vehicle design. These results have included the effect of facility pressure on the non-equilibrium state of the freestream test gas and the comparison of surface catalytic activity between air and nitrogen. The fundamental learning resulting from this study will provide insight into future design of experiments on the Orion reentry capsule.

\section{Acknowledgements}

This work was sponsored under grant \#M5146247101/FA9550-04-1-0341 through the University of Minnesota and AFOSR. The views and conclusions contained herein are those of the authors and should not be interpreted as necessarily representing the official policies or endorsements, either expressed or implied, of the AFOSR or the U.S. Government.

Orion shoulder heating work in the Discussion section was supported by the Project Orion Program Office at NASA Johnson Space Center, Houston, TX through the U.S. Army Aviation and Missile Command contract \#W31P4Q-04-C-R095. 


\section{References}

${ }^{1}$ Holden, M.; Wadhams, T.; MacLean, M.; and Walker, B. "Experimental Studies in Hypersonic Flows for Facility and Code Validation." AIAA Paper 2007-1304. 45 ${ }^{\mathrm{TH}}$ AIAA Aerospace Sciences Meeting \& Exhibit, Reno, NV: 8-11 January 2007.

${ }^{2}$ MacLean, M.; Wadhams, T.; Holden, M.; Parker, R. "A Computational Analysis of Thermochemical Studies in the LENS Facilities.” AIAA Paper 2007-0121. 45 ${ }^{\mathrm{TH}}$ AIAA Aerospace Sciences Meeting \& Exhibit, Reno, NV: 8-11 January 2007.

${ }^{3}$ Parker, R.; Wakeman, T; MacLean. M.; and Holden, M. "Measuring Nitric Oxide Freestream Velocity Using Quantum Cascade Lasers at CUBRC". AIAA Paper 2007-1329. 45 ${ }^{\mathrm{TH}}$ Aerospace Sciences Meeting \& Exhibit. Reno, NV: 8-11 January 2007.

${ }^{4}$ Lu, F.K. and Marren, D.E. Eds. Advanced Hypersonic Test Facilities. AIAA Progress in Astronautics and Aeronautics Series: Vol 198. Chapter 4. Reston, VA: American Institute of Aeronautics and Astronautics, 2002.

${ }^{5}$ Holden, M.S.; Wadhams, T.P.; and Candler, G.V. "Experimental Studies in the LENS Shock Tunnel and Expansion Tunnel to Examine Real-Gas Effects in Hypervelocity Flows". AIAA Paper 2004-0916. January 2004.

${ }^{6}$ Parker, R.; Wakeman, T.; Holden, M.; and MacLean, M. "Measuring NO Freestream Concentration Using Quantum Cascade Lasers at CUBRC". AIAA Paper 2006-0926. 44 ${ }^{\mathrm{TH}}$ Aerospace Sciences Meeting \& Exhibit. Reno, NV: 9-12 January 2006.

${ }^{7}$ Wright, M.J.; Bose, D.; and Candler, G.V. "A Data Parallel Line Relaxation Method for the Navier-Stokes Equations”. AIAA Journal. Vol 36, no 9. Pgs 1603 - 1609. Sept 1998.

${ }^{8}$ MacCormack, R.W. and Candler, G.V. "The Solution of the Navier-Stokes Equations Using Gauss-Seidel Line Relaxation". Computers and Fluids. Vol 17, No 1. Pgs 135 - 150. 1989.

${ }^{9}$ Candler, G.V. "Chemistry of External Flows". Aerothermochemistry for Hypersonic Technology: Von Karman Institute for Fluid Dynamics Lecture Series. VKI LS 1995-04.

${ }^{10}$ Landau, L. and Teller, E. "Theory of Sound Dispersion”. Physikalische Zeitschrift der Sowjetunion. Vol 10, no 34.1936.

${ }^{11}$ Millikan, R. and White, D. "Systematics of Vibrational Relaxation". Journal of Chemical Physics. Vol 39, no 12. Pgs 3209 $-3213.1963$.

${ }^{12}$ Camac, M. " $\mathrm{CO}_{2}$ Relaxation Processes in Shock Waves". Fundamental Phenomena in Hypersonic Flow. J.G. Hall Ed. Cornell University Press. Pgs $195-215,1964$.

${ }^{13}$ Park, C.; Howe, J.T.; Jaffe, R.J.; and Candler, G.V. "Review of Chemical-Kinetic Problems of Future NASA Missions II: Mars Entries". Journal of Thermophysics and Heat Transfer. Vol 8, no 1. Pgs 9-23. 1994.

${ }^{14}$ Park, Chul. "Assessment of Two-temperature Kinetic Model for Ionizing Air". AIAA Paper 87-1574. AIAA 22 ${ }^{\text {ND }}$ Thermophysics Conference. Honolulu, HI: 8-10 June 1987.

${ }^{15}$ Marrone, P.V. and Treanor, C.E. "Chemical Relaxation with Preferential Dissociation from Excited Vibrational Levels". The Physics of Fluids, Vol 6, no 9. Pgs 1215 - 1221. September 1963.

${ }^{16}$ Palmer, G.E. and Wright, M.J. "A Comparison of Methods to Compute High Temperature Gas Viscosity". Journal of Thermophysics and Heat Transfer. Vol 17, no 2. Pgs 232 - 239. 2003.

${ }^{17}$ Palmer, G.E. and Wright, M.J. "A Comparison of Methods to Compute High Temperature Gas Thermal Conductivity". AIAA Paper 2003-3913. Jun 2003.

${ }^{18}$ Gupta, R.; Yos, J.; Thompson, R.; and Lee, K. "A Review of Reaction Rates and Thermodynamic and Transport Properties for an 11-Species Air Model for Chemical and Thermal Nonequilibrium Calculations to 30000 K". NASA RP-1232. August 1990.

${ }^{19}$ Ramshaw, J.D. "Self-consistent Effective Binary Diffusion in Multicomponent Gas Mixtures”. Journal of Non-Equilibrium Thermodynamics. Vol 15, no 3. Pgs 295 - 300. 1990.

${ }^{20}$ Baldwin, B.S. and Lomax, H. "Thin Layer Approximation and Algebraic Model for Separated Turbulent Flows". AIAA Paper 78-0257. Huntsville, AL: 1978.

${ }^{21}$ Spalart, P.R. and Allmaras S.R. “A One-Equation Turbulence Model for Aerodynamic Flows”. AIAA Paper 92-0439. 30"TH Aerospace Sciences Meeting \& Exhibit. Reno, NV: 6-9 Jan, 1992.

${ }^{22}$ Menter, F.R. "Two-Equation Eddy-Viscosity Turbulence Models for Engineering Applications". AIAA Journal. Vol 32, no 8. Pgs $1598-1605$. August 1994.

${ }^{23}$ Brown, James. "Turbulence Model Validation for Hypersonic Flow". AIAA Paper 2002-3308. $8^{\mathrm{TH}}$ Thermophysics and Heat Transfer Conference. St. Paul, MN: 24 - 26 Jun 2002.

${ }^{24}$ Catris S. and Aupoix B. "Improved Turbulence Models for Compressible Boundary Layers." AIAA Paper 98-2696. $2^{\text {ND }}$ Theoretical Fluid Mechanics Meeting: Albuquerque, NM, June 1998.

${ }^{25}$ Saunders, D.; Yoon, S.; and Wright, M. "An Approach to Shock Envelope Grid Tailoring and Its Effect on Reentry Vehicle Solutions," AIAA Paper 2007-0207. 45 ${ }^{\mathrm{TH}}$ Aerospace Sciences Meeting \& Exhibit. Reno, NV: 8-11 January 2007.

${ }^{26}$ Candler, Graham V. "Hypersonic Nozzle Analysis Using an Excluded Volume Equation of State". AIAA Paper 20055202. $38^{\mathrm{TH}}$ AIAA Thermophysics Conference, Toronto, CA: 6 - 9 June 2005.

${ }^{27}$ Lordi, J.A. and Mates, R.E. Non-equilibrium Expansions of High-Enthalpy Airflows. Cornell Aeronautical Laboratory Report, ARL 64-206. November 1964.

${ }^{28}$ MacLean, M.; Candler, G.; and Holden, M. "Numerical Evaluation of Flow Conditions in the LENS Reflected ShockTunnel Facilities". AIAA Paper 2005-0903. 43 ${ }^{\text {RD }}$ Aerospace Sciences Meeting \& Exhibit. Reno, NV: 10-14 January 2005.

${ }^{29}$ Nompelis, I. and Candler, G. "Investigation of Hypersonic Double-Cone Flow Experiments at High Enthalpy in the LENS Facility." AIAA Paper 2007-203. 45 ${ }^{\mathrm{TH}}$ AIAA Aerospace Sciences Meeting \& Exhibit, Reno, NV: 8-11 January 2007. 
${ }^{30}$ MacLean, M. and Holden, M. "Numerical Assessment of Data in Catalytic and Transitional Flows for Martian Entry." AIAA Paper 2006-2946. $9^{\mathrm{TH}}$ AIAA/ASME Joint Thermophysics and Heat Transfer Conference, San Francisco, CA: 5-8 June 2006.

${ }^{31}$ MacLean, M. and Holden, M. "Catalytic effects on Heat transfer Measurements for Aerothermal Studies with CO2." AIAA Paper 2006-0182. 44 ${ }^{\mathrm{TH}}$ Aerospace Sciences Meeting \& Exhibit. Reno, NV: 9-12 January 2006.

${ }^{32}$ Nompelis, I.; Candler, G.; and Holden, M. "Effect of Vibrational Nonequilibrium on Hypersonic Double-Cone Experiments". AIAA Journal Vol 41, no 11. Pgs 2162 - 2169. November 2003.

${ }^{33}$ Miller, J.; Tannehill, J.; Wadawadigi, G.; Edwards, T.; and Lawrence, S. "Computation of Hypersonic Flows with Finite Catalytic Walls," Journal of Thermophysics and Heat Transfer, Vol 9, no 3. Pgs 486 - 493. July - September, 1995.

${ }^{34}$ Jochen Marschall, private communication. 22 May 2008.

${ }^{35}$ Singh, H.; Coburn, J.W.; abd Graves, D.B. "Recombination Coefficients of O and N Radicals on Stainless Steel," Journal of Applied Physics. Vol 88, no 6. Pgs 3748 - 3755. 15 September 2000.

${ }^{36}$ Breshears, W.D. and Bird, P.F. "Effect of Oxygen Atoms on the Vibrational Relaxation of Nitrogen," Journal of Chemical Physics, Vol 48, no 10. Pgs 4768 - 4773. 1968.

${ }^{37}$ Laux, T., Feigl, M., Stöckle, T., and Auweter-Kurtz, M., "Estimation of the Surface Catalyticity of PVD-Coatings by Simultaneous Heat Flux and LIF Measurements in High Enthalpy Air Flows," AIAA Paper 2000-2364, June 2000.

${ }^{38}$ Copeland, R.A., Pallix, J.B., and Stewart, D.A., "Surface Catalyzed Production of NO from Recombination of N and O Atoms," Journal of Thermophysics and Heat Transfer, Vol. 12, pp. 496-499. 1998.

${ }^{39}$ Pejaković, D., Marschall, J., Duan, L., and Martin, M.P., "Nitric Oxide Production from Surface Recombination of Oxygen and Nitrogen Atoms," Journal of Thermophysics and Heat Transfer, Vol 22, no 2, Pgs 178 - 186. 2008.

${ }^{40}$ Granier, A.; Nicolazo, F.; Vallee, C.; Goullet, A.; Turban, G.; and Grolleau, B. "Diagnostics in $\mathrm{O}_{2}$ Helicon Plasmas for $\mathrm{SiO}_{2}$ Deposition," Plasma Sources Science and Technology. Vol 6. Pgs 147 - 156. May 1997.

${ }^{41}$ Booth, J.P. and Sadeghi, N. "Oxygen and Fluorine Atom Kinetics in Electron Cyclotron Resonance Plasmas by TimeResolved Actinometry," Journal of Applied Physics, Vol 70, no 2. Pgs 611 - 620. 15 July 1991

${ }^{42}$ Fay Riddell.

${ }^{43}$ Wadhams, T.; Cassady, A.; Mundy, E.; MacLean, M.; and Holden, M. "Experimental Studies of the Aerothermal Characteristics of the Project Orion CEV Heat Shield in High Speed Transitional and Turbulent Flows," To Be Published at the $47^{\mathrm{TH}}$ AIAA Aerospace Sciences Meeting \& Exhibit, Orlando, FL: 5 - 8 January 2009. 